\title{
Identifying and Estimating the Effects of Unconventional Monetary Policy: How to Do It And What Have We Learned?
}

\author{
Barbara Rossi* \\ ICREA-Univ. Pompeu Fabra, Barcelona GSE, and CREI
}

This Draft: July 31, 2020

\begin{abstract}
The recent financial crisis led central banks to lower their interest rates in order to stimulate the economy until they hit the zero lower bound. How should one identify monetary policy shocks in unconventional times? Are unconventional monetary policies as effective as conventional ones? And has the monetary policy transmission mechanism changed in the zero lower bound era? This article aims at providing an overview of the econometric challenges and solutions to the identification of monetary policy shocks in unconventional times as well as a survey of their empirical effects on the economy.

*Corresponding author: Barbara Rossi, CREI, Univ. Pompeu Fabra, c. Ramon Trias Fargas 25-27, 08005 Barcelona, Spain. E-mail: barbara.rossi@upf.edu.

Acknowledgments. I thank J. Abbring, J. Campbell, F. Canova, L. Hoesch, T. Sekhposyan and seminar participants at the 2018 Royal Economic Society, the 2019 IAAE and the 2019 Society for Nonlinear Dynamics and Econometrics conferences for comments; P. Tiozzo and Y. Wang for research assistance; N. Kocherlakota and J. Morley for discussions; and the Fundación BBVA scientific research grant (PR16_DAT_0043) on Analysis of Big Data in Economics and Empirical Applications. Supported by the Cerca Programme/Generalitat de Catalunya as well as the European Research Council (grant agreement No. 615608). The BGSE acknowledges financial support from the Spanish Ministry of Economy and Competitiveness, through the Severo Ochoa Programme for Centres of Excellence in R\&D (SEV-2015-0563).

J.E.L. Codes: C1, C01, E5. Keywords: Shock Identification, VARs, Zero Lower Bound, Unconventional Monetary Policy, Monetary Policy, External Instruments, Forward Guidance.
\end{abstract}




\section{Introduction}

Are unconventional monetary policies as effective as conventional ones? And has the monetary policy transmission mechanism changed in an era where interest rates are at the zero lower bound? This article aims at providing a broad overview of the recent literature on the identification of unconventional monetary policy shocks and the estimation of their effects on both financial as well as macroeconomic variables. As we will discuss, unconventional monetary policy tools could be not only used again should economies find themselves at the zero lower bound in the future: they have also played, and may well continue to play, an important role in conventional times as well. Hence, these are very important issues in practice.

At the zero lower bound (ZLB), the monetary policy instrument (the short-term interest rate) cannot be lowered further in order to stimulate the economy. A decade ago, the zero lower bound problem was considered a rare phenomenon, mainly associated with the Bank of Japan choice to keep short-term interest rates close to zero for several years; however, the recent financial crisis has shown that it is not such a rare phenomenon, after all. In fact, the crisis led central banks to lower their interest rates in order to stimulate the economy until they hit the zero lower bound in many advanced countries. For example, in the US, the central bank kept interest rates close to zero between December 2008 and December 2015. More recently, due to the COVID-19 pandemic, US short-term interest rates became close to the zero lower bound again in 2020; given the international nature of the pandemic, other countries are likely to share a similar issue. Given that the prospects of slow recoveries and long periods of very low interest rates are becoming the norm, many economists believe that we are likely to face the zero lower bound problem often in the future as well. As Kocherlakota (2018) notes, recent empirical estimates of the natural real rate of interest (that is, the real interest rate consistent with output equaling its natural rate and stable inflation) based on Laubach and Williams' (2003) methodology suggest that it has fallen steadily in the last ten years; Del Negro et al. (2018) and Mertens and Johannsen (2018) find similar results. Thus, even small adverse shocks may push interest rates below the zero lower bound. For example, in the presence of another financial crisis, even if minor, pre-existing low real interest rates imply that the central bank will be unable to insulate the economy. As a result, aggregate output may decline substantially, thus contributing to another long recession and a prolonged stay at the zero lower 
bound.

Since traditional expansionary policies of lowering interest rates cannot be implemented at the zero lower bound, central banks used alternative monetary policies to stimulate the economy via so-called Quantitative Easing ("QE") measures. Monetary policy at the zero lower bound has been generally dealt with by using two kind of unconventional monetary policy interventions: large scale asset purchases and forward guidance. Large scale asset purchases ("LSAP") refer to purchases of assets of private financial firms to inject liquidity and counteract the tightening in financial markets. Forward guidance refers to announcements that are intended to change the public belief about future central banks' actions. For example, the central bank could announce that it could keep interest rates "lower for longer", or it could say that interest rates would rise "more gradually for longer", meaning that the path of future interest rates will be different from the anticipated one.

Clearly, in the presence of unconventional monetary policy, the traditional approach to the identification and estimation of monetary policy faces new econometric challenges. For example, we simply cannot identify the impact of a variable that has no variance, nor include that variable in a VAR; samples are typically short and it is problematic to merge pre- and post-zero lower bound data; furthermore, it is unclear which variables to include in a VAR to describe unconventional monetary policy. Hence, how to identify and estimate monetary policy shocks in unconventional times is a difficult task, in practice. We will discuss the econometric challenges faced by researchers when identifying monetary policy shocks in unconventional times as well as estimating their effects on the economy, and shed light on the empirical findings so far.

It is important to note that unconventional monetary policy has played a role in conventional times as well. For example, episodes of forward guidance date back to $2004 .^{1}$ Hence, unconventional monetary policy tools may also continue to play an important role even outside the zero lower bound.

The focus in this article is on VAR-based models. Hence, we will review techniques such as shadow rates (Wu and Xia, 2016, 2019; Krippner, 2013a); heteroskedasticity-based identification (Rigobon, 2003; Wright, 2012); high-frequency identification (Kuttner, 2001; Bernanke and Kuttner,

\footnotetext{
${ }^{1}$ E.g. the announcement on January 28, 2004, substantially affected financial markets even if it was not accompanied by any movements in the short-term interest rate - see Gurkaynak, Sack and Swanson (2005, p. 56) for a detailed discussion of such event.
} 
2005; Gürkaynak et al., 2005), external instruments (Gertler and Karadi, 2015; Montiel-Olea et al., 2012; Stock and Watson, 2018), and Functional VARs (Inoue and Rossi, 2018). Alternatively, one can estimate the effects of unconventional monetary policy shocks in structural DSGE models, in which case the shocks would be already identified by construction. For example, Kulish, Morley and Robinson (2017) estimate a model where the central bank can fix the interest rate for an extended period of time; Campbell, Fisher, Justiniano and Melosi (2017) apply a relatively standard DSGE model to characterize forward guidance in the wake of the 2008 financial crisis, which yielded actionable insight into past policy failures and successes; Cai et al. (2018) demonstrate that incorporating financial frictions into a model allows it to mimic the slow recovery after the financial crisis. ${ }^{2}$ The trade-off between the two approaches is that VAR-based methods are more robust to misspecification, which is an important issue in the latest financial crisis, when some DSGE models did not fare well (see Kuo, Inoue and Rossi, 2019, on empirical methods to detect misspecification in structural models); on the other hand, DSGE models may allow economists to incorporate outside information and narratives regarding the nature of structural changes.

The paper is structured as follows. The next section reviews the econometric approaches for identifying monetary policy shocks; Section 3 reviews the empirical findings on the effects of unconventional monetary policy on asset prices, macroeconomic variables, surveys as well as international variables. Section 4 concludes.

\section{Econometric Approaches to the Identifica- tion of Monetary Policy Shocks}

\subsection{Traditional Approaches}

Consider the following structural VAR model of order $p$ for the $(n \times 1)$ vector of variables $X_{t}$ :

$$
B(L) X_{t}=c+\varepsilon_{t},
$$

\footnotetext{
${ }^{2}$ Other examples include: Wu and Zhang (2017), who propose a shadow-rate New Keynesian model; Chen et al. (2012), who embed LSAP in a structural model; and Chung, Laforte, Reifschneider and Williams (2012), who simulate a DSGE model.
} 
where $B(L)=B_{0}-B_{1} L-\ldots-B_{p} L^{p}$ is a lag polynomial, $c$ is a vector of constants and $\varepsilon_{t}$ is an $(n \times 1)$ vector of zero-mean, serially uncorrelated structural shocks with identity covariance matrix: $E\left(\varepsilon_{t} \varepsilon_{t}^{\prime}\right)=I_{n} \cdot{ }^{3}$

Under invertibility and other standard assumptions, the structural VAR can be rewritten as a structural MA model (Watson, 1994):

$$
X_{t}=k+\Theta_{0} \varepsilon_{t}+\Theta_{1} \varepsilon_{t-1}+\ldots+\Theta_{q-1} \varepsilon_{t-(q-1)}+\Theta_{q} \varepsilon_{t-q}+\ldots
$$

Define the corresponding reduced-form $\operatorname{VAR}(\mathrm{p})$ as:

$$
A(L) X_{t}=\mu+u_{t},
$$

where the lag polynomial $A(L)=I-A_{1} L-\ldots-A_{p} L^{p}$ is such that $A_{j}=\mathcal{B} B_{j}$, $\mu=\mathcal{B} c, \mathcal{B} \equiv B_{0}^{-1}$ and, in particular, ${ }^{4}$

$$
u_{t}=\mathcal{B} \varepsilon_{t} .
$$

The reduced-form VAR model, eq. (3), is the model typically estimated, since a linear system of equations with homoskedastic and serially uncorrelated errors and the same regressors in each equation can be efficiently and conveniently estimated equation by equation by OLS (see Hayashi, 2001), giving estimates of $A_{1}, A_{2}, \ldots, A_{p}, \mu$ and the symmetric matrix $\Omega \equiv E\left(u_{t} u_{t}^{\prime}\right)$. The challenge is to recover the structural parameters of interest in eq. (1) from the reduced-form VAR, eq. (3). The identification problem arises because the number of estimated parameters in eq. (3) is $n^{2} \times p+n+n(n+1) / 2$ while the number of structural parameters is $n^{2} \times(p+1)+n$ - see Watson (1994); hence, one needs to impose $n(n-1) / 2$ identification restrictions on eq. (1). ${ }^{5}$ In fact, note that $u_{t}=\mathcal{B} \varepsilon_{t}$ and $E\left(\varepsilon_{t} \varepsilon_{t}^{\prime}\right)=I_{n}$ imply $E\left(u_{t} u_{t}^{\prime}\right)=\mathcal{B B}^{\prime}$; this, together with $\Omega \equiv E\left(u_{t} u_{t}^{\prime}\right)$, implies that $\mathcal{B B}^{\prime}=\Omega$ : the latter is a (nonlinear) system of equations that, in general, requires $n(n-1) / 2$ restrictions to identify the parameters.

A traditional approach to identification involves a recursive approach (Sims, 1980). Define the $(n \times n)$ lower-triangular matrix $P$ such that

$$
P^{\prime} P=\Omega \text {. }
$$

\footnotetext{
${ }^{3}$ The assumption that the variances of the structural shocks are normalized to one is assumed to hold in this sub-section but not necessarily in the next ones.

${ }^{4}$ We use the notation $\mathcal{B}$ to define the individual elements of the inverse matrix, and keep them distinct from the inverses of the matrix elements.

${ }^{5}$ We assume that the VARs satisfy the usual covariance stationarity assumptions. We are already imposing that $E\left(\varepsilon_{t} \varepsilon_{t}^{\prime}\right)=I_{n}$.
} 
The $n(n-1) / 2$ zero restrictions in the lower-triangular matrix $P$ make the system of equations (5) just-identified. The matrix $P=\mathcal{B}$ is known as the Cholesky factor of $\Omega$.

This approach requires that the researcher is able to identify zero restrictions that can be justified based on economic grounds. An area where the recursive approach has been used extensively is the identification of monetary policy shocks - see Christiano et al. (1999) for an overview. To illustrate the approach, we will focus on the case where $n=3$ and the variables used in the VAR are output $\left(y_{t}\right)$, inflation $\left(\pi_{t}\right)$ and the short-term interest (federal funds) rate $\left(r_{t}\right.$, henceforth FFR), as in the benchmark VAR in Stock and Watson (2001). Let $X_{t}=\left(\pi_{t}, y_{t}, r_{t}\right)^{\prime}$ and let $B_{s, i j}$ denote the $i$-th row and $j$-th column scalar value in the matrix $B_{s}$. Hence, the structural VAR we consider is: ${ }^{6}$

$$
\left(\begin{array}{ccc}
B_{0,11} & B_{0,12} & B_{0,13} \\
B_{0,21} & B_{0,22} & B_{0,23} \\
B_{0,31} & B_{0,32} & B_{0,33}
\end{array}\right)\left(\begin{array}{c}
\pi_{t} \\
y_{t} \\
r_{t}
\end{array}\right)=c+B_{1} X_{t-1}+\ldots+B_{p} X_{t-p}+\left(\begin{array}{c}
\varepsilon_{1, t} \\
\varepsilon_{2, t} \\
\varepsilon_{3, t}
\end{array}\right)
$$

The traditional "backward-looking" Taylor rule for monetary policy is:

$$
r_{t}=r^{*}+\phi_{\pi}\left(\pi_{t}-\pi^{*}\right)+\phi_{y}\left(y_{t}-y^{*}\right)+\varepsilon_{m p, t},
$$

where $r^{*}$ is the desired interest rate, $\left(\pi_{t}-\pi^{*}\right)$ is the deviation of the inflation rate from its desired level and $\left(y_{t}-y^{*}\right)$ is the output gap. ${ }^{7}$ The residual $\varepsilon_{m p, t}$ is the monetary policy shock. Note that the Taylor rule can be rewritten by redefining the constant term as: $r_{t}=\kappa+\phi_{\pi} \pi_{t}+\phi_{y} y_{t}+\varepsilon_{m p, t}$. If output and inflation in the above rule are pre-determined when the monetary authority sets interest rates, inflation or output cannot react to the interest rate set by the central bank. This timing assumption implies two zero restrictions, namely that inflation and output cannot react contemporaneously to the FFR, i.e.

$$
B_{0,13}=B_{0,23}=0 .
$$

${ }^{6}$ Differently from Stock and Watson (2001), our VAR features output instead of unemployment; however, empirical results are similar no matter which of the two is used (Christiano et al., 1999).

${ }^{7}$ For simplicity, we are ignoring the lagged value of the interest rate (or other lagged values). 
This implies

$$
\left(\begin{array}{ccc}
B_{0,11} & B_{0,12} & 0 \\
B_{0,21} & B_{0,22} & 0 \\
B_{0,31} & B_{0,32} & B_{0,33}
\end{array}\right)\left(\begin{array}{c}
\pi_{t} \\
y_{t} \\
r_{t}
\end{array}\right)=c+B_{1} X_{t-1}+\ldots+B_{p} X_{t-p}+\left(\begin{array}{c}
\varepsilon_{1, t} \\
\varepsilon_{2, t} \\
\varepsilon_{3, t}
\end{array}\right)
$$

where the last eq. in (9) can be rewritten as:

$$
r_{t}=-B_{0,33}^{-1} B_{0,31} \pi_{t}-B_{0,33}^{-1} B_{0,32} y_{t}+f\left(X_{t-1}, \ldots, X_{t-p}, c\right)+B_{0,33}^{-1} \varepsilon_{3, t},
$$

and $f\left(X_{t-1}, \ldots, X_{t-p}, c\right)$ denotes a linear function of past values of $X$ and the constant. Note that these restrictions are sufficient to eliminate the endogeneity problem for the purpose of identifying the monetary policy shock and estimating its effects on the economy. In fact, as shown in the Appendix, by inverting $B_{0}$ after imposing the restrictions in eq. (8), one obtains a matrix $\mathcal{B}$ where $\mathcal{B}_{13}=\mathcal{B}_{23}=0$. That is,

$$
\left(\begin{array}{l}
\pi_{t} \\
y_{t} \\
r_{t}
\end{array}\right)=\left(\begin{array}{ccc}
\mathcal{B}_{11} & \mathcal{B}_{12} & 0 \\
\mathcal{B}_{21} & \mathcal{B}_{22} & 0 \\
\mathcal{B}_{31} & \mathcal{B}_{32} & \mathcal{B}_{33}
\end{array}\right)\left\{c+B_{1} X_{t-1}+\ldots+B_{p} X_{t-p}+\left(\begin{array}{c}
\varepsilon_{1, t} \\
\varepsilon_{2, t} \\
\varepsilon_{3, t}
\end{array}\right)\right\}
$$

Eq. (11) implies that both $\pi_{t}$ and $y_{t}$ are functions only of $\varepsilon_{1, t}, \varepsilon_{2, t}$ and past values of the endogenous variables, but not of $\varepsilon_{3, t}$. On the other hand, from eq. (9), $r_{t}$ is a function of $\pi_{t}, y_{t}, \varepsilon_{3, t}$ and past values of the endogenous variables. Note that the error term is such that $E\left(\varepsilon_{3, t} \mid \pi_{t}, y_{t}, X_{t-1}\right)=$ $E\left(\varepsilon_{3, t} \mid \varepsilon_{1, t}, \varepsilon_{2, t}, X_{t-1}\right)=0$, where the first equality follows from the fact that, under eq. (8), both $\pi_{t}$ and $y_{t}$ are functions only of $\varepsilon_{1, t}, \varepsilon_{2, t}$ and past values of the endogenous variables, and the last follows from the fact that shocks are unpredictable given past information and are mutually independent. Thus, the OLS regression of $r_{t}$ on $\pi_{t}, y_{t}$ and past values of the endogenous variables in eq. (10) recovers consistent estimates of the parameters and of the monetary policy shock (up to a scale factor), as $\varepsilon_{m p, t}=B_{0,33}^{-1} \varepsilon_{3, t}$. Hence, the impulse response coefficients can be estimated by directly regressing the macroeconomic variables on $\varepsilon_{3, t}, \varepsilon_{3, t-1}, \ldots$

However, note that the two zero restrictions imposed by eq. (8) are not sufficient to identify the other shocks in the structural VAR, namely the output and the inflation shocks. In order to identify all the shocks and all the parameters, one needs one more restriction. A typical restriction is that 
$B_{0,12}=0$. Clearly, under the restrictions $B_{0,13}=B_{0,23}=B_{0,12}=0, B_{0}$ is lower-triangular and the remaining parameters in $B_{0}$ can be estimated as the inverse of the Cholesky factor of $\Omega$. Often, such additional restrictions are used in practice even if the primary object of interest is only the monetary policy shock: the researcher imposes lower-triangularity and identifies all the shocks while not taking seriously the restrictions that identify the shocks that are not of interest. That is, the researcher explores alternative lowertriangularity restrictions, all of which have in common $B_{0,13}=B_{0,23}=0$. In this example, such alternative restrictions would include $B_{0,12}=0$ and $B_{0,21}=0$. The researcher then verifies that the conclusions regarding the economic shock of interest are robust to the alternative identification schemes.

\subsection{Why Do Traditional Approaches Fail at the ZLB?}

Clearly, the traditional recursive identification approach described in the previous sub-section cannot be used at the zero lower bound since the short-term FFR rate is zero, and the VAR cannot be estimated with an endogenous variable that is constant and equal to zero. ${ }^{8}$ In addition, note that most of

\footnotetext{
${ }^{8}$ To overcome this problem, a researcher might consider a VAR with long-term interest rates (or spreads) instead of the short-term interest rate. That is, $X_{t}=\left(\pi_{t}, y_{t}, r_{t}^{\text {long }}\right)^{\prime}$, where $r_{t}^{\text {long }}$ is the long-term interest rate (e.g. the 2-year or the 5-year maturity rate). For example, Walentin (2014) includes mortgage spreads as a measure of monetary policy in a VAR and the identifying restriction is that mortgage spreads do not affect aggregate quantities or consumer prices on impact, but can affect the policy rate or house prices. By using estimates of decreases in mortgage spreads from works on asset prices during QE episodes, he can then estimate that QE1 had a peak effect on consumption and GDP equal to about 3 percent. Chen et al. (2016) study the effects of a US QE shock on emerging economies, where the shock is measured as an interest rate spread. While this approach may avoid the problem of working with endogenous variables that equal zero, as the longterm interest rate is typically positive even at the ZLB, it is unclear which long-term maturity to use, and empirical results may depend on that choice. Furthermore, financial variables are important in unconventional times, and once they are included in the VAR, the usual conventional timing restrictions are not valid anymore. In fact, within a period, central banks may be responding to movements in financial variables or to underlying variables that are correlated to financial variables and left out of the VAR (see Gertler and Karadi, 2015, p. 4). In addition, working with long-term rates will make comparisons across conventional and unconventional monetary policy regimes very difficult, as the shocks are identified using different methodologies/ variables in the two sub-samples unless the same long-term rate is used in both conventional and unconventional periods, as in Hanson and Stein (2015). However, using a long-term rate in both conventional
} 
the reaction to monetary policy in unconventional times takes place at the time in which such policies are announced (as opposed to the time they are implemented in practice). For example, forward guidance announcements communicating the public that the central bank plans to keep interest rates "lower for longer" affects the economy immediately, if expectations are rational. Similarly, for the same reason, unexpected LSAP announcements may affect the economy at the time they are announced, not necessarily when they are implemented. Again, the traditional approach would miss these important effects and new approaches are needed.

Alternative identification schemes that overcome the aforementioned problems and, hence, are suitable at the zero lower bound include using a shadow rate instead of the FFR at the zero lower bound (Wu and Xia, 2016, 2019; Krippner, 2013a; among others), heteroskedasticity-based identification (Wright, 2012), High Frequency Identification (HFI, Kuttner, 2001), external instruments (Gertler and Karadi, 2015; Montiel-Olea et al., 2012; Stock and Watson, 2018), and Functional VARs (Inoue and Rossi, 2018).

Importantly, note that these approaches should be viewed as complements rather than substitutes. For example, both shadow rate models and Functional VARs use information on the whole term structure of interest rates: while the former uses it to estimate a short-term rate that is consistent with movements in long-term rates according to a model of the term structure, the latter uses the whole term structure directly. Similarly, the HFI approach allows researchers to identify a series of exogenous shocks that can be used as external instruments as well. Also, one could view exogenous movements in the shadow rate as an external instrument rather than a variable to include in the VAR. Finally, one could use a heteroskedasticitybased identification within the Functional VAR. Thus, the approaches can be creatively combined. We review each of these identification schemes in the following sub-sections.

\subsection{Shadow Rates}

The shadow rate is the nominal interest rate that would prevail in the absence of the zero lower bound. The shadow rate is typically estimated from a finance model, which assumes the existence of a "shadow" yield curve, that

and unconventional periods implies that the estimated effects of monetary policy in the conventional period may be different from those obtained by the typical approach, which are based on using the short-term rate. 
is a yield curve which is linear in Gaussian factors and hence can become negative at short maturities, even though the actual short-term rate is the maximum of the shadow rate and zero. The shadow rate is the shortest maturity rate from the estimated shadow yield curve. See Wu and Xia (2016) for a detailed description on how their shadow rate is constructed. ${ }^{9}$ It is important to clarify that the shadow rate is not the level of interest rates that a central bank would want to set based on economic conditions (i.e. it is not a Taylor rule); rather, it is the level of the short-term rate implied by a statistical model of the term structure with a zero lower bound. For example, it will take negative values in unconventional monetary policy environments to signal a policy that is more accommodative than a zero short-term (policy) rate by taking into account the effects on longer-maturity rates. When the zero lower bound is not binding, the shadow rate equals the short-term interest rate. Krippner (2013a,b, 2016), Christensen and Rudebusch (2014), Wu and Xia (2016) and Bauer and Rudebusch (2016) have proposed shadowrate measures of interest rates that have been used to quantify the stance of US monetary policy in unconventional times. Lemke and Vladu (2017), Kortela (2016) and Wu and Xia (2018) focus on European data. In particular, $\mathrm{Wu}$ and Xia (2018) propose a shadow rate for the euro area where interest rates have reached negative levels. Kim and Singleton (2012) and Ichiue and Ueno (2013) develop term structure models at the zero lower bound for Japan. Lombardi and Zhu (2014) propose an alternative model-free shadow rate based on a factor model, extracting information from a large dataset of variables linked to central banks' monetary policies.

An advantage of using shadow rates is that one can easily compare conventional and unconventional sub-samples, since, by construction, the shadow rate is the same as the short-term interest rate outside the zero lower bound. Hence, they are an intuitive and convenient indicator of the stance of monetary policy in both conventional and unconventional periods.

However, since the shadow rate is determined from an estimated yield curve model, in practice the estimate may depend on the model used by the researcher. Furthermore, since the shadow rate is model-based, its estimated value depends on the full sample, which could be a problem for forecasting out-of-sample. One should, in principle, also deal with the additional uncertainty surrounding its estimation. Finally, the shadow rate is a theo-

\footnotetext{
${ }^{9}$ See Johannsen and Mertens (2018) for an alternative approach to shadow rates, based on time series models.
} 
retical concept and does not correspond to interest rate values used in actual transactions.

An alternative way to summarize the stance of monetary policy in an indicator is to use the "Expected Time to Zero" (for this, as well as alternative measures, see Krippner, 2016). This indicator is the horizon at which the short-term rate will reach zero, conditional on the shadow rate being negative at the current time. It is a less convenient measure to use in practice than the shadow rate, since the time series is available only when the shadow rate is negative.

\subsection{Heteroskedasticity-based Identification}

The heteroskedasticity-based approach to identification exploits additional restrictions deriving from the variance of the shocks changing over time. Assume that the variance of the structural errors changes at a given point in time (due to particular events) from $E\left(\varepsilon_{t} \varepsilon_{t}^{\prime}\right)=\Lambda_{A}$ to $E\left(\varepsilon_{t} \varepsilon_{t}^{\prime}\right)=\Lambda_{B}$, where $\Lambda_{A}$ and $\Lambda_{B}$ are diagonal matrices with elements $\lambda_{i A}$ and $\lambda_{i B}$, respectively. In our context, in order to identify a monetary policy shock, it is reasonable to assume that, on days of a monetary policy announcement, the variance of the monetary policy shock is bigger than its variance on any other day. Hence, monetary policy announcement days identify the two sub-samples.

If the researcher aims at identifying all the shocks using the heteroskedasticitybased method, he/she can assume that the variances of all structural shocks are different in the relevant sub-samples. Recall that $\Omega$ denotes the variance of the reduced-form shocks, and let $\Omega_{A}$ and $\Omega_{B}$ denote such variance in the two sub-samples. Thus, following Rigobon (2003), from equation (4), $E\left(\varepsilon_{t} \varepsilon_{t}^{\prime}\right)=\Lambda_{A}$ and $E\left(\varepsilon_{t} \varepsilon_{t}^{\prime}\right)=\Lambda_{B}$, we have:

$$
\Omega_{A}=\mathcal{B} \Lambda_{A} \mathcal{B}^{\prime} \text { and } \Omega_{B}=\mathcal{B} \Lambda_{B} \mathcal{B}^{\prime}
$$

Eq. (12) is sufficient to identify the structural parameters of interest after normalizing either $\Lambda_{A}$ or $\Lambda_{B}$ to the identity matrix (as $\Lambda_{A}, \mathcal{B}$ and $\Lambda_{B}$ are not separately identifiable). In fact, eq. (12) is a system of $n(n+1)$ equations $^{10}$ in $\left(n^{2}+n\right)$ unknowns. ${ }^{11}$

\footnotetext{
${ }^{10}$ The number of equations in each of the two systems of equations in (12) is $n(n+1) / 2$, as the $(n \times n)$ matrices $\Omega_{A}$ and $\Omega_{B}$ are symmetric.

${ }^{11}$ There are $n^{2}$ unknown parameters in $\mathcal{B}$ and $n$ unknown parameters in the diagonal matrix $\Lambda_{B}$ - assuming $\Lambda_{A}$ has been normalized to the identity matrix.
} 
On the other hand, if the researcher only wants to identify the monetary policy shock, it is sufficient to assume that only the variance of the monetary policy shock changes across sub-samples. This assumption provides one restriction that identifies the monetary policy shock as follows. Following Wright (2012), note that $u_{t}=\mathcal{B} \varepsilon_{t}$ implies that

$$
u_{t}=\sum_{i=1}^{n} \mathcal{B}_{\cdot i} \varepsilon_{i, t}
$$

where $\varepsilon_{i, t}$ is the $i$-th structural shock and $\mathcal{B}_{\cdot i}$ is the $i$-th $(n \times 1)$ column vector of $\mathcal{B}$. Let the monetary policy shock be $\varepsilon_{3, t}$. The identification restriction is that the variance of the monetary policy shock, i.e. $\operatorname{var}\left(\varepsilon_{3, t}\right) \equiv \lambda_{3}$, changes at time $t$ from $\lambda_{3 A}$ to $\lambda_{3 B}$, while the variance of all the other shocks remains constant: $\lambda_{i A}=\lambda_{i B}$ for every $i \neq 3$. From eq. (13), calculating the variance of the reduced form shocks in the two sub-samples, we have $\Omega_{A}=\sum_{i=1}^{n} \mathcal{B}_{{ }_{i}} \lambda_{i A} \mathcal{B}^{\prime}{ }_{i}$ and $\Omega_{B}=\sum_{i=1}^{n} \mathcal{B}_{. i} \lambda_{i B} \mathcal{B}_{. i}^{\prime}$, a system of equations that identifies the structural parameters of interest. In fact, $\Omega_{A}-\Omega_{B}=\sum_{i=1}^{n} \mathcal{B}_{\cdot i}\left(\lambda_{i A}-\lambda_{i B}\right) \mathcal{B}_{. i}^{\prime}$ $=\left(\lambda_{3 A}-\lambda_{3 B}\right) \mathcal{B}_{3} \mathcal{B}_{\cdot 3}^{\prime}$. Normalizing $\lambda_{3 A}-\lambda_{3 B}=1$, and letting $\widehat{\Omega}_{A}$ denote the estimate of $\Omega_{A}$ (and similarly for $\widehat{\Omega}_{B}$ ), one can then estimate $\mathcal{B}_{3.3}$ using a minimum distance estimator by choosing $\mathcal{B}_{.3}$ in order to minimize:

$$
\underset{\mathcal{B}_{3}}{\operatorname{argmin}} d\left(\mathcal{B}_{\cdot 3}\right)^{\prime}\left[V_{\text {vech }\left(\Omega_{A}\right)}+V_{\text {vech }\left(\Omega_{B}\right)}\right]^{-1} d\left(\mathcal{B}_{\cdot 3}\right),
$$

where $d\left(\mathcal{B}_{3}\right) \equiv \operatorname{vech}\left(\widehat{\Omega}_{A}-\widehat{\Omega}_{B}\right)-\operatorname{vech}\left(\mathcal{B}_{\cdot 3} \mathcal{B}_{\cdot 3}^{\prime}\right)$, and $V_{v e c h}\left(\Omega_{A}\right)$ and $V_{\operatorname{vech}\left(\Omega_{A}\right)}$ are the variances of $\widehat{\Omega}_{A}$ and $\widehat{\Omega}_{B}$, respectively.

The approach we describe above is implemented using data at a frequency (daily) that is higher than the frequency of the other variables in the VAR (typically monthly or quarterly), and hence shares some similarities with the HFI/event-study approach that will be discussed in the next sub-section. However, the heteroskedasticity-based identification has also been used to study monetary policy outside the event-study approach - see Brunnermeier, Palia, Sastry and Sims (2018).

Clearly, an important assumption behind the heteroskedasticity-based identification is that there is no other structural change in the parameters of the model. Note that this assumption prevents structural changes both in the variances of the other shocks as well as in the other parameters of the $\operatorname{VAR}\left(B_{0}, B_{1}, \ldots, B_{p}\right)$. On the other hand, the advantage of the methodology is that it does not necessarily require knowledge of the time of the monetary policy shock, which may be inferred directly from the volatility in the data. 
Identification via heteroskedasticity uses the fact that a switch in policy creates additional estimated parameters, hence it helps with identification, whose problem is typically caused by the fact that researchers need to identify more structural parameters than those they can estimate in the data. The switch can be thought of as a dummy variable instrument that can be used to identify the shock. However, the switch needs to be exogenous and unaffected by the policy shift that the researcher is attempting to estimate. Typically, regimes changes caused by occasionally binding constraints (such as the zero lower bound) are not exogenous; in fact, whether the zero lower bound binds or not may depend on the structural shocks. Mavroeidis (2020) develops a methodology to estimate SVARs with a variable subject to an occasionally binding constraint that can be used to identify monetary policy shocks at the zero lower bound while avoiding the endogeneity problem.

\subsection{High-Frequency Identification and Event-Study Ap- proaches}

In a seminal paper, Kuttner (2001) proposed to identify monetary policy shocks as the changes in financial markets' expectations in a short window of time around a monetary policy announcement. In particular, Kuttner (2001) measured monetary policy shocks from the change in the daily federal funds futures rate around FOMC announcements. ${ }^{12}$ In the pre-zero lower bound period, Bernanke and Kuttner (2005) study the effects of conventional monetary policy on stock markets, while Gürkaynak, Sack and Swanson (2005) show that, based on this identification, monetary policy announcements contain valuable information above and beyond the actual changes in the shortterm interest target rate, such as forward guidance. More in detail, the latter estimate forward guidance by the (second) factor extracted from a panel of federal funds and eurodollar futures on days of monetary policy announcements. The factor is rotated such that it is associated with no change in the current month federal funds future rate, and it is referred to as the "path factor". They show that the latter indeed plays a big role on days when for-

\footnotetext{
${ }^{12}$ In this approach, an implicit but realistic assumption is that risk premia do not change over such a short time interval; otherwise the monetary policy shock would also capture changes in risk premia. This assumption is supported by Piazzesi and Swanson (2008), while Miranda-Agrippino (2016) argues that, if there are not enough risk-neutral investors to make hedges on central bank's announcements costless, futures should exhibit predictable returns over the event horizon, which is what she finds.
} 
ward guidance is implemented. Campbell et al. (2012) extend their analysis to the zero lower bound period.

The HFI is implemented in a simple regression estimated on monetary policy announcement dates only:

$$
\Delta X_{i, t}=\alpha+\beta \varepsilon_{m p, t}+\gamma W_{t}+u_{t}
$$

where $t=\left\{t_{1}, t_{2}, \ldots, t_{M P}\right\}$ indicates the dates identified by monetary policy announcements, $\varepsilon_{m p, t}$ is the surprise component of the policy rate change due to monetary policy (that is, the change in the policy rate, $\Delta r_{t}$, in the time period identified by the monetary policy announcement) and $\Delta X_{i, t}$ is the change in a variable of interest over the same time interval - hence, the terminology "high-frequency" identification. $W_{t}$ is a set of control variables that will be discussed below, and $u_{t}$ is a residual.

Several assumptions need to be satisfied in order to interpret $\beta$ as the response of $X_{i, t}$ to a monetary policy shock. First, clearly, changes in interest rates $\left(\Delta r_{t}\right)$ may not necessarily be due to monetary policy; therefore, a key condition in this identification strategy is that the change be measured in a short window of time around the announcement, to avoid the measure being contaminated by other shocks that might happen within the same time period. Hence, this methodology is also sometimes referred to as an "event-study", due to the fact that the identification really relies on selecting specific episodes that allow researchers to extract the exogenous component of monetary policy. ${ }^{13}$ Key examples of such episodes in the US include the LSAP announcement of November 25, 2008 (which started the first quantitative easing program - QE1); the LSAP announcement of August 10, 2010 (which started QE2), the maturity extension program on September 21, 2011, etc. However, forward guidance announcements have also played a role during conventional times. In particular, an important example described in Gürkaynak, Sack and Swanson (2005) is the announcement of January 28,2004 , where there was no change in the policy rate but markets heavily reacted to unanticipated news released in the announcement.

A second key assumption is that the announcement has to be unanticipated. If the announcement is anticipated, the estimate of $\beta$ will underestimate the effects. In the US, this might be the case at the early stages of $\mathrm{QE}$, but less so in the later stages (Kuttner, 2018).

\footnotetext{
${ }^{13}$ Event-studies go back to Fama, Fisher, Jensen and Roll (1969) - see Ball (2017).
} 
Another implicit assumption in the event-study methodology is that the news is immediately incorporated in prices by rational expectations and efficient markets, which could be debatable assumptions at times of severe disruptions, such as those associated with financial crises. If there are delayed effects, a narrow window around the announcements will exclude them. As the choice of the window may be important, typically studies perform some robustness analyses to the window size.

Finally, several studies calculate a cumulative response to a monetary policy event by summing the estimated $\beta^{\prime} s$ across all the announcements related to the event; when doing so, the underlying assumption is that the effects are permanent (Reichlin, 2011).

The HFI/event-study approach faces several challenges. A first challenge is that, as we mentioned, the identified shock $\left(\varepsilon_{m p, t}\right)$ may not be a pure monetary policy shock, since it might be contaminated by either (i) other shocks (e.g. news about the state of the economy) or (ii) information that the central bank releases about the future state of the economy in its announcements (Campbell, Fisher, Justiniano and Melosi, 2017). Regarding (i), one could include in $W_{t}$ variables that control for information that jointly affects $\Delta X_{i, t}$ and $\Delta r_{t}$, such as the release of economic news. Also, the time period identified by the dummy variable $d_{t}$ is typically carefully chosen to directly isolate the change in $X_{i, t}$ that is free of economic news releases. ${ }^{14}$ Regarding (ii), Romer and Romer (2000) find empirical evidence that central banks have superior predictive ability relative to the private sector, and Campbell, Fisher, Justiniano and Melosi (2017) document the existence of an information channel by finding that expansionary monetary policy surprises are associated with upward revisions in unemployment rate survey forecasts - a fact that can be rationalized if the market participants update their estimate of the state of the economy to be worse than they expected even though monetary policy was expansionary. When informational effects are empirically important, researchers have available methodologies to clean the shocks by regressing them on central bank's own forecasts (e.g. Miranda-Agrippino and Ricco, 2018) or identify the information channel using sign restrictions on its effects on stock prices (Jarocinski and Karadi, 2018). On the other hand, informational effects are a concern if central banks' forecasts are more

\footnotetext{
${ }^{14}$ Note that the state of the economy may affect the reaction of interest rates to the announcements even when measured within a narrow window, for example because of the state of the business cycle or the level of market uncertainty will affect market reactions (see Reichlin, 2011, p. 191-192, for a discussion).
} 
accurate than the private sector's; however, the forecasting advantage of central banks relative to the private sector was significant in the past (e.g. over the sample considered by Romer and Romer, 2000) but has disappeared in the most recent period (Rossi and Sekhposyan, 2016, and Hoetsch, Rossi and Sekhposyan, 2019).

Another challenge is that, while the estimate of the impact effect is straightforward, the calculation of the dynamic response is complicated by the presence of the dummy variable and it is not clear how to estimate an impulse response function in this approach. Finally, HFI assumes that the monetary policy shock is measured exactly by the change in the target rate in the selected window (i.e. there is no measurement error). The Functional VAR and external instrument approaches described in the next two sections address each of these concerns, respectively.

\subsection{External Instruments and the Local Projection-IV Approach}

An alternative way to identify unconventional monetary policy shocks is to use external sources of information - that is, external instruments (MontielOlea et al., 2012). External instruments are variables that are correlated with the shock of interest but not with other shocks. They are not necessarily the shock of interest, as they might contain some measurement error, but, as long as they are uncorrelated with the other shocks in the system, they can be used to identify the shock of interest; however, they need to be exogenous. An example of a monetary policy instrument in the conventional period is the Romer and Romer (2004) narrative shock. Another example is a shock identified via HFI. Note that there is a substantial difference between the implementation of the HFI approach and that of the external instrument approach where the shock is identified via HFI: in the HFI approach, one estimates eq. (14) by OLS, where the regressor is the HFI monetary policy shock and is observed; in the external IV approach, one estimates eq. (14) by 2 SLS, where the regressor is the interest rate and the instrument is the HFI monetary policy shock.

There are two leading approaches to implement external instruments in practice: VARs with external instruments and Local Projection Instrumental Variable regressions - see Stock and Watson (2018) for the relationship between the two. We will consider each of them in turn in what follows, 
focusing on unconventional monetary policy applications.

\subsubsection{VARs with External Instruments}

In the VAR-based approach (Gertler and Karadi, 2015), one needs a valid measure of a policy rate at the zero lower bound to include in the VAR as an endogenous variable. Clearly, the short-term interest rate cannot be used, as it is zero; therefore, a medium- or long-term interest rate is typically used, which will be denoted by $r_{t}^{\ell}$.

Consider a VAR where $X_{t}$ is an $(n \times 1)$ vector of endogenous variables including $r_{t}^{\ell}$, which is ordered last (without loss of generality). To illustrate the approach, let us focus on the $n=3$ case in eq. (6), where $r_{t}$ is replaced by $r_{t}^{\ell}$. The responses to the monetary policy shock, $\varepsilon_{m p, t}$, can be estimated by considering the portion of the structural VAR related to the monetary policy shock; from eqs. (3-4), the latter is:

$$
X_{t}=\sum_{j=1}^{p} A_{j} X_{t-j}+\mathcal{B}_{\cdot 3} \varepsilon_{m p, t},
$$

where $\mathcal{B}_{3}$ is the column of $\mathcal{B}$ that multiplies the monetary policy shock. Assume that there is an instrument $Z_{t}$ such that $E\left(Z_{t} \varepsilon_{m p, t}\right) \neq 0$ while $E\left(Z_{t} \varepsilon_{j, t}\right)=0$ for every shock $\varepsilon_{j, t}$ that is not a monetary policy shock. In Gertler and Karadi (2015), the instrument comes from the HFI literature and it is the surprise in fed fund and eurodollar futures in a short window of time around monetary policy announcements. Then, as shown in Gertler and Karadi (2015), $\mathcal{B}_{3}$ can be estimated by 2SLS as follows. In the first step, regress $u_{3, t}$ (the reduced form residual ordered last in the VAR, and associated with the policy indicator $r_{t}^{l}$ ) on the instrument $Z_{t}$ to obtain the fitted value $\widehat{u}_{3, t}$, whose variation is only due to exogenous movements in $Z_{t}$. In the second step, one obtains a consistent estimate of $\mathcal{B}_{3}$ (up to a constant of proportionality) by regressing the remaining reduced form residuals $\left[u_{1, t}, u_{2, t}\right]^{\prime}$ on $\widehat{u}_{3, t}$.

Note that a crucial element of this approach is the instrument choice: it is not always clear which one to choose and instruments may potentially be weak - see Section 2.6.3 below for a discussion. Also, it is may not be obvious which maturity of the policy rate to choose. For example, in the US, some have argued that the central bank target horizon is two years, while Gertler and Karadi (2015) use the one-year government bond rate since, for the two year rate, the HFI instrument they selected turns out 
to be weak. It is also not clear which maturity to use when considering other countries. Note also that using a rate that is not the same as the rate commonly used in conventional times makes the exercise of comparing conventional and unconventional monetary policies difficult.

\subsubsection{LP-IV}

Another convenient way to estimate impulse responses in the external instrument approach is via Local Projection Instrumental Variable (LP-IV) regressions. The LP regression (Jordà, 2005, 2019) follows from the structural MA representation in eq. (2):

$$
X_{t+h}=k+\Theta_{h} \Theta_{0}^{-1} X_{t}+u_{t+1, t+h},
$$

where $u_{t+1, t+h}$ is a function of $\varepsilon_{t+h}, \varepsilon_{t+h-1}, \ldots, \varepsilon_{t+1}, \varepsilon_{t-1}, \varepsilon_{t-2, \ldots}$ Again, for simplicity, we focus on the case $n=3$, where $\varepsilon_{3, t}$ is the monetary policy shock. The LP-IV approach estimates directly the responses from eq. (16) using an instrument. ${ }^{15}$ Suppose the researcher is interested in the response of the $j$-th variable in eq. (16), $X_{i, t}$, to the monetary policy shock. Let $\Theta_{h, i}$. denote the $j$-th row in $\Theta_{h}$ and $\Theta_{h, i j}$ denote the $i$-th row and $j$-th column element of $\Theta_{h}$. Let the exogenous instrument for the monetary policy shock $\varepsilon_{3, t}$ be denoted by the scalar $Z_{t}$ - that is, $E\left(Z_{t} \varepsilon_{3, t}\right) \neq 0$ but $E\left(Z_{t} \varepsilon_{i, t}\right)=0$ for every $i \neq 3 .^{16}$ Then, the LP-IV estimator is:

$$
\frac{E\left(X_{i, t+h} Z_{t}\right)}{E\left(X_{i, t} Z_{t}\right)}=\frac{E\left(\Theta_{h, i} \Theta_{0}^{-1} X_{t} Z_{t}\right)}{E\left(\Theta_{0, i} \cdot \varepsilon_{t} Z_{t}\right)}=\frac{E\left(\Theta_{h, i} \Theta_{0}^{-1} \Theta_{0} \varepsilon_{t} Z_{t}\right)}{E\left(\sum_{j=1}^{n} \Theta_{0, i j} \varepsilon_{j, t} Z_{t}\right)}=\frac{\Theta_{h, i 3} E\left(\varepsilon_{3, t} Z_{t}\right)}{\Theta_{0, i 3} E\left(\varepsilon_{3, t} Z_{t}\right)}
$$

which recovers the parameter of interest, $\Theta_{h, i 3}$, up to scale. The LP-IV approach is particularly convenient to use in panels.

\subsubsection{A note on Instruments' Relevance}

An important condition required in this approach to identification is that the instruments be relevant (i.e. $E\left(X_{t} Z_{t}\right) \neq 0$ ): if the latter condition does

\footnotetext{
${ }^{15}$ Note that external instruments are used as instruments and are not included among the variables $X_{t}$ in the VAR.

${ }^{16}$ Future shocks are assumed to be uncorrelated with past values of $X$ as well as past values of $Z$.
} 
not hold, the instruments are weak and the external IV approach delivers inconsistent estimates.

The presence of weak instruments is typically detected by a first-stage F-statistic (Stock and Yogo, 2005). However, the first-stage F-statistic relies on the assumption of independent and identically distributed (i.i.d.) errors both in the first stage regression as well as in the structural equation (see Stock, Wright and Yogo, 2002).

In the VAR-based approach, if the VAR is correctly specified, the error term in the structural equation is i.i.d. Thus, if the error term in the firststage regression (i.e. the regression where $X_{t}$ is regressed on the instrument $Z_{t}$ ) is also i.i.d. then a standard first-stage F-statistic can be used. However, while this assumption can be defended in cross-section data, it is often too stringent for time-series data: any omitted, serially correlated variable in the structural equation and any serial correlation in $X_{t}$ not fully explained by $Z_{t}$ would invalidate the assumption, in which case the usual first-stage F-statistic cannot be used. In the LP-IV approach, instead, the errors in the LP-IV regression $\left(u_{t+1, t+h}\right)$ are possibly serially correlated by construction since, even if the underlying VAR is correctly specified, the error term is a moving average. ${ }^{17}$

Montiel-Olea and Pflueger (2013) discuss a generalization of the firststage F-test in the presence of serial correlation that can be used to judge instrument strength in the presence of one endogenous regressor. However, researchers are often interested in confidence intervals for the structural parameters in eq. (15) or they might have more than one endogenous regressor: Ganics, Inoue and Rossi (2018) discuss confidence intervals for the structural estimates in eq. (17) as well as confidence intervals for the strength of identification that are valid in the presence of both heteroskedasticity and serial correlation, and allow for multiple endogenous regressors.

\footnotetext{
${ }^{17}$ In fact, suppose eq. (15) holds and $p=1$. Then, $X_{t+h}=A_{1}^{h} X_{t}+$ $\sum_{j=0}^{h-1} A_{1}^{j} \mathcal{B}_{\cdot 3} \varepsilon_{m p, t+h-j}$, where $\Theta_{h}=A_{1}^{h}$ and $u_{t+1, t+h}=\sum_{j=0}^{h-1} \mathcal{B}_{3} A_{1}^{j} \varepsilon_{m p, t+h-j}$. Thus, the error term $u_{t+1, t+h}$ is an MA $(h-1)$ even when the underlying VAR is correctly specified. Note that the serial correlation induced by LP-IV affects eq. (16) and not necessarily the first-stage regression; however, the latter can be separately affected by the presence of serial correlation.
} 


\subsection{VARs and LP-IVs with Functional Shocks}

VARs and LP-IVs with functional shocks (Inoue and Rossi, 2018) offer an alternative approach to identify monetary policy shocks. In the VAR/LP-IV with functional shocks, the shock is a function, not a scalar value, and the impulse-response functions are defined as the responses of the endogenous variables to the functional shock itself. The methodology is relevant for the unconventional monetary policy literature as the notion of a scalar shock, like the exogenous movement in the short-term interest rate, can be extended to a monetary policy "event", summarized by the exogenous shift in the entire yield curve associated with unexpected monetary policy decisions. The latter can include both forward guidance as well as announcements of future asset purchases. While in the VAR with functional shocks the latter are included as an additional variable, the the LP-IV with functional shocks the latter are included as external variables.

To be concrete, consider a Nelson and Siegel (1987) and Diebold and Li (2006) model of the term structure, where the movements in the yield curve are described by time-varying level, curvature and slope:

$$
r_{t}(\tau)=\beta_{1, t}+\beta_{2, t}\left(\frac{1-e^{-\lambda \tau}}{\lambda \tau}\right)+\beta_{3, t}\left(\frac{1-e^{-\lambda \tau}}{\lambda \tau}-e^{-\lambda \tau}\right),
$$

where $r_{t}(\tau)$ is the yield as a function of the maturity $\tau$. Then, the "functional shock" is a combination of movements in level, curvature and slope on the day of the monetary policy announcement and is defined as:

$\varepsilon_{m p, t}(\tau) \equiv \Delta r_{t}(\tau) \cdot d_{t}=\Delta \beta_{1, t}+\Delta \beta_{2, t}\left(\frac{1-e^{-\lambda \tau}}{\lambda \tau}\right)+\Delta \beta_{3, t}\left(\frac{1-e^{-\lambda \tau}}{\lambda \tau}-e^{-\lambda \tau}\right)$

where $d_{t}$ is a dummy variable equal to one if there is a monetary policy shock at time $t$ and $\Delta$ denotes time differences: $\Delta r_{t}(\tau) \equiv r_{t}(\tau)-r_{t-1}(\tau)$. The notation $\varepsilon_{m p, t}($.$) highlights the fact that the monetary policy shock is$ a function. To extract the exogenous component of monetary policy, the change in the yield curve is calculated in a short interval of time around monetary policy announcements.

The main difference between this and other identification approaches is that, in this approach, the shock itself is a function, while in the others the shock is typically a scalar. Defining a "functional shock" has some advantages. First, it views the shock to the term structure due to changes in level, 
curvature and slope as a joint event. Second, it may be more robust to the situation where the number of factors changes over time. In fact, consider the two shocks depicted in Figure 1. They have the same intercept and slope, yet they are very different, as the shock depicted by a continuos line has no effect on long-term interest rates while the one depicted by the dotted line does. In other words, the shape of the shock might be different in each event and viewing the shock itself as a function across maturities allows to capture these changes over time. As a result, as Inoue and Rossi (2018) show, the functional approach provides a more comprehensive measure of monetary policy shocks. Third, the functional shock has the advantage of being defined in the same way no matter whether one considers conventional or unconventional monetary policy regimes, and hence can be used to study both in a unified manner - although the shape of the shock can change across regimes to capture different policy aspects.

Inoue and Rossi (2018) show how to trace out the effects of monetary policy shocks in the economy via VARs using a procedure called "VARs with functional shocks". They consider a reduced-form VAR model with an economic variable $X_{t}$ and a function $f_{t}(\cdot):^{18}$

$$
\begin{aligned}
X_{t} & =c_{1}+\phi_{1,1} X_{t-1}+\phi_{1,2} \int w(\tau) f_{t-1}(\tau ; \lambda) d \tau+u_{X, t}, \\
f_{t}(\tau ; \lambda) & =c_{2}(\tau)+\phi_{2,1}(\tau) X_{t-1}+\phi_{2,2} f_{t-1}(\tau ; \lambda)+u_{f, t}(\tau ; \lambda),
\end{aligned}
$$

where the function is a linear combination of $q$ time-varying factors $\left(\beta_{j, t}\right.$, where $t$ denotes time) with coefficients that are functions of the maturity $\tau$ and tuning parameters $\lambda$ :

$$
f_{t}(\tau ; \lambda)=\sum_{j=1}^{q} \beta_{j, t} g_{j}(\tau ; \lambda) .
$$

They show that the model (20)-(22) can be estimated by a VAR that includes $X_{t}$ and the time-varying factors $\beta_{j, t}$. The response of the macroeconomic variables $\left(X_{t+h}\right)$ to the monetary policy shock $\left(\varepsilon_{m p, t}().\right)$ is a combination of the changes in each of the time-varying components that drive the functional shock:

\footnotetext{
${ }^{18}$ In the Nelson and Siegel (1987) model described by eq. (18), the function $f_{t}(\cdot)$ is $r_{t}(\tau)$.
} 


$$
\frac{\partial X_{t+h}}{\partial \varepsilon_{m p, t}(.)}=\sum_{j=1}^{q} \Lambda_{j, h}\left(\Delta \beta_{j, t} d_{t}\right),
$$

where $\Lambda_{j, h} \equiv \frac{\partial X_{t+h}}{\partial \Delta \beta_{j, t}^{\prime}}$ is estimated in the VAR, while $\Delta \beta_{j, t} d_{t}$ is estimated by the change in the term structure in a short window of time around the monetary policy announcement.

The idea to define the shock as a multi-dimensional object, and then derive an impulse response function to it, differentiates the functional approach from other approaches, which either include several interest rates at longer maturities in the VAR or include some factors describing the yield curve, and then separately calculate the responses to each maturity or each factor. Note that a factor model is not an essential ingredient in the VAR with functional shocks approach: alternatively, one can be more flexible and use the raw yields directly (as in Inoue and Rossi, 2019). Note also that one can describe the term structure by principal components, where the first two factors would be reminiscent of the level and slope factors defined in Gürkaynak, Sack and Swanson (2005); the difference between the approaches is not the particular factor structure behind the term structure, but that the latter, unlike Inoue and Rossi (2018), consider shocks to level and slope factors separately, not as a joint event.

\subsection{Sign-Restrictions}

Sign-restrictions is an identification approach that has often been used to identify monetary policy shocks in conventional times (Faust, 1998; Canova and De Nicolo, 2002; Uhlig, 2005); examples of works that have used signrestrictions to identify unconventional monetary policy shocks include Baumeister and Benati (2013), D'Amico and King (2017) and Debortoli, Gali and Gambetti (2019).

In order to identify the monetary policy shock, one needs to impose that the responses of some variables to specific structural shocks have a certain sign. Typically, one randomly generates a large number of uncorrelated shocks ${ }^{19}$ and then keeps only the responses that have the desired sign. The challenge in imposing sign restrictions when identifying unconventional monetary policy shocks is that it may be unclear what the response of

\footnotetext{
${ }^{19}$ See Kilian and Lutkepohl (2017) for specific algorithms.
} 
macroeconomic variables to monetary policy in unconventional times is.

Once one has identified the shocks, the typical procedure is use counterfactual analyses to assess the effects of monetary policy on the economy. Counterfactual analyses are typically calibrated on changes in interest rates estimated from existing high-frequency studies to quantify the effects on the macroeconomic variables of interest.

\section{Measuring the Effects of Unconventional Monetary Policy: What Have We Learned?}

The identification approaches described in the previous section have been widely used, separately or in combination, to shed light on the effects of unconventional monetary policy in the data. This section reviews what we have learned from these empirical analyses.

The effects of unconventional monetary policy on economic variables can be measured either in terms of high-frequency financial variables, such as long-term yields and other asset prices, or low-frequency macroeconomic variables, such as output and inflation. We consider the former in the next section and the latter in Section 3.2, and in both cases we focus on the US The literature has also analyzed the effects in countries other than the US or the spillovers of monetary policy across countries, which we review in Section 3.3, as well as the effects of monetary policy on agents' expectations measured by surveys, which we overview in Section 3.4.

\subsection{The Effects on Long-Term Yields and Other Asset Prices: the US Experience}

We first focus on the US evidence, where unconventional monetary policy operated via both forward guidance announcements as well as a series of LSAPs (known as QE1, QE2 and QE3) and maturity extension programs. See Gagnon and Sack (2018) for a detailed description of each of the QE episodes and Campbell, Fisher, Justiniano and Melosi (2017) for a description of how forward guidance evolved over time in the US. ${ }^{20}$

\footnotetext{
${ }^{20}$ See also Swanson (2011) for an operation similar to QE implemented in the US in the 1960 s.
} 
Overall, the literature agrees that the empirical effects of unconventional monetary policy are significant on long-term yields and other asset prices. These results hold across a variety of identification procedures.

Using a heteroskedasticity-based identification, Wright (2012) finds that unconventional monetary policy shocks have a large effect on 10-year Treasury yields and long-maturity corporate yields, while the effect on two-year yields is very small. A monetary policy shock that decreases ten year yields by 25 basis points will instantaneously also decrease AAA and BAA rates by half as much. Thus, the long-term effects are not only on government yields but are transmitted to the private sector as well. He also finds that shortterm Treasury Inflation Protected Securities (TIPS) rates rise but long-term ones fall; he interprets the evidence as suggesting that the boost in demand due to the policy also increases short- and medium-term inflation but, at the same time, LSAP concentrates on nominal securities that push longer term rates even lower.

The high-frequency/event-study identification uncovers similarly substantial responses and has generated a large literature. The studies can be distinguished in: (i) approaches that estimate the effects of announcements, either about forward guidance or future purchases of securities; and (ii) approaches that estimate the effects of central bank's actual purchases of securities. The difference between the two approaches is that using changes in assets at the moment they are purchased - as opposed to the time in which the purchase is announced - might uncover smaller effects, as the effects might have already been anticipated at the time of the announcement via rational expectations and promptly incorporated in asset prices by efficient markets. On the other hand, if markets are not efficient, there could be additional effects when actual purchases take place.

Regarding (i), one of the early studies that evaluates the effectiveness of forward guidance, dating way before the zero lower bound, is Gürkaynak, Sack and Swanson (2005), who show that their path factor ${ }^{21}$ provides additional explanatory power to movements in asset prices around monetary policy announcements and substantially affects Treasury bond yields at several maturities. For example, a 1\% increase in the factor increases long-term ( 5 and 10 year) Treasury yields by about 30 basis points on average in conventional times. Campbell, Evans, Fisher and Justiniano (2012) find that a similar results holds during the zero lower bound period, except that the

\footnotetext{
${ }^{21}$ See the description in Section 2.5.
} 
effects of the path factor are bigger; they also find that AAA and BAA long maturity bonds are affected by it. ${ }^{22}$ Gilchrist, Lopez-Salido and Zakrajsek (2015) focus on estimating the effects on real borrowing costs. They identify two unconventional shocks: the change in the two-year Treasury yield in a 30 minutes window around the announcement and the change in the ten year yield orthogonal to the two-year one in the same window. They estimate the effects of the shocks on asset prices by regressing the latter on the two shocks and imposing cross-equation restrictions that ensure the orthogonality. By comparing conventional and unconventional monetary policy regimes, they find that conventional monetary policy steepens the yield curve (a 10 basis point reduction in the 2-year yield induces a decline of 4 basis points in the 10-year yield) while unconventional policy flattens it (the same reduction in the 2 year yield leads to a 16 basis point decline in the 10 year yield). They also find that most of the movement in nominal yields is reflected in real rates and hence, monetary policy actions are transmitted fully to real business borrowing costs and significantly to households' real borrowing costs in mortgage markets. Hanson and Stein (2015) also find effects of unconventional shocks on long-term real rates: a 100 basis point increase in the two-year nominal Treasury yield leads to a 42 basis point increase in the ten-year forward overnight rate.

Regarding announcements related to purchases of securities during the zero lower bound, Gagnon, Raskin, Remache and Sack (2011) and Krishnamurthy and Vissing-Jorgensen (2011) estimate the jumps in asset prices in a daily window of time around each of such announcements; the overall effect of monetary policy is obtained by summing all the jumps related to the same policy event. ${ }^{23}$ In particular, Gagnon, Raskin, Remache and Sack (2011) document that QE1 did lead to a large decrease in interest rates on announcement dates. They also find that LSAPs successfully flatten the yield curve; this means that, since short-term yields are constant at the zero lower bound, long-term yields decrease. ${ }^{24}$ In terms of magnitude, LSAPs appear to reduce ten-year term premia somewhere between 30 and 100 basis points. ${ }^{25}$

\footnotetext{
${ }^{22}$ A 100 basis point increase in the path factor increases AASA/BAA yields by 30-35 basis points.

${ }^{23}$ For example, QE1 includes the initial announcement plus subsequent FOMC meetings and speeches that followed and further extended the program.

${ }^{24}$ See also Doh (2010).

${ }^{25}$ An alternative approach undertaken in Gagnon, Raskin, Remache and Sack (2011) is to regress term premia on a set of explanatory variables, and then perform counterfactuals.
} 
Krishnamurthy and Vissing-Jorgensen (2011) find similar results; they also find that the magnitude of the effects depends on the episode; furthermore, expected inflation increases as a result of the first two QE episodes, implying larger reductions in real than in nominal rates. Wright (2012) also performs a HFI/case study exercise, identifying the monetary policy shock as the first principal component of 2, 5, 10, and 30 year Treasury bond futures in a 2-hour window of time around the announcement; according to this identification, a one standard deviation monetary surprise decreases ten-year Treasury yields by 12 basis points. ${ }^{26}$

Overall, the consensus is that LSAP purchases cumulatively reduced yields on 10-year Treasuries by about 100 basis points (Borio and Zabai, 2016; Kuttner, 2017). Greenlaw, Hamilton, Harris and West (2018) extend the set of announcement dates and find slightly smaller effects than the consensus in the literature. Overall, it is fair to say that studies based on eventstudies agree that the effect of QE1 was between 100 and 200 basis points, while QE2 had smaller effects around 20 to 40 basis points, where the actual amount depends on the specific asset under consideration (Kuttner, 2018, Table 2), ${ }^{27}$ as well as the choice of the window size.

Regarding (ii), D'Amico and King (2013) estimate the effects of the actual central bank's large quantities of government backed securities purchased in the secondary markets (LSAP) during the financial crisis. They estimate a regression (on the days of the purchases) of the change in the price of the securities on the quantity purchased, controlling for the maturity of the asset. More in detail, D'Amico and King (2013) estimate eq. (14), where $d_{t}=1$ on a day of a central bank purchase, $\Delta X_{i, t}$ is the change in the price of the security and $\varepsilon_{m p, t}$ is the quantity of the security that is purchased; the control variables $W_{t}$ include, for example, the asset maturity. They find that, on average, Treasury purchases decreased yields by about 30 basis points across the yield curve over the whole program, and by a further 4 basis points on the days in which purchases took place. The former mostly affected securities between 10 to 15 years of maturity while the latter were concentrated on maturities lower than 15 years. They conclude that LSAP

This approach, however, assumes that the explanatory variables are exogenous and that the estimated coefficients do not change between conventional times and the ZLB period.

${ }^{26}$ As a comparison, before the ZLB, it would need a 100 basis point surprise cut in the fed funds rate to decrease the ten-year Treasury yields by the same amount.

${ }^{27}$ How precise these estimates are is unclear, as we have few observations of such announcements. 
had economically sizeable effects. ${ }^{28}$

As QE announcements also include forward guidance and not just information regarding LSAP, typically high-frequency identification based on announcements will estimate the joint effects of both. Rogers, Scotti and Wright (2014) attempt to disentangle the two by assuming that a monetary policy surprise that decreases all the yields is an expansionary LSAP shock, while a shock that rotates the yield curve by pushing short rates down and long rates up is a forward guidance shock. They find that LSAP shocks have the most significant effects on asset prices; however, forward guidance shocks appear to lower an option-implied index of interest rate volatility, possibly because they reduce uncertainty about future monetary policy.

Regarding the persistence of the effects, Wright (2012), for example, finds that the effects last up to several weeks and the half-life is about 2-3 months. ${ }^{29}$ Note, however, that the HFI approach requires measuring the change in asset prices in a short-window of time around the announcement: a short window is more likely to ensure that identification holds, as it avoids asset prices being affected by anything other than monetary policy; but, at the same time, it might be less likely to capture long-run effects - in other words, one typically focuses on an immediate reaction, which may be short-lived by construction.

\footnotetext{
${ }^{28} \mathrm{~A}$ more model-based approach is taken by Hamilton and $\mathrm{Wu}$ (2012), who estimate a model that summarizes the relationship between the maturity structure and the term structure of interest rates, and use it for counterfactual analyses to gauge the effects of changing the maturity structure. The challenges in this approach are the presence of endogeneity (the correlation might be due to the fact that the Central bank responds to interest rates) and the assumption of stability of the relationship over time. They find that changes in the maturity structure can be successfully used to flatten the yield curve.

${ }^{29}$ Wright (2012) offers two possible interpretations of the quick reversal: one is that monetary policy was indeed a stimulus to the economy; the other is that financial markets over-reacted on impact.
} 
Table 1. Selected Empirical Studies on the Effects of Unconventional Monetary Policy on High Frequency Financial Variables: Yields and Other Asset Prices

Identification Strategy

References

$\begin{array}{ll}\text { Shadow Rate } & \cdot \text { N/A } \\ \text { Heteroskedasticity } & \cdot \text { Wright (2012) } \\ \text { HFI / Event-study } & \cdot \text { Gürkaynak, Sack and Swanson (2005) } \\ & \cdot \text { Doh (2010) } \\ & \cdot \text { Krishnamurthy and Vissing-Jorgensen (2011) } \\ & \cdot \text { Gagnon, Raskin, Remache and Sack (2011) } \\ & \cdot \text { Meaning and Zhu (2011) } \\ & \cdot \text { Campbell, Evans, Fisher and Justiniano (2012) } \\ & \cdot \text { D'Amico and King (2013) } \\ & \cdot \text { Bauer and Rudebusch (2014) } \\ & \cdot \text { Gilchrist, Lopez-Salido and Zakrajsek (2015) } \\ & \cdot \text { Hanson and Stein (2015) } \\ \text { External-IV } & \cdot \text { Rogers, Scotti and Wright (2018) } \\ \text { Functional VAR } & \cdot \text { N/A } \\ \text { Sign Restrictions } & \cdot \text { N/A }\end{array}$

Note to the table. The table lists selected empirical studies on unconventional monetary policy.

While the literature clearly agrees that unconventional monetary policy affects long-term yields, the difficulty is in knowing why. Standard finance theory says that, in efficient markets, it is not important which kind of debt the central bank holds: simply swapping one kind of debt (money) for another (long-term bonds), as in LSAP programs, should not have any effect. According to Bernanke (The Financial Times, October 14, 2014): "The problem with QE is it that works in practice, but it doesn't work in 
theory." Purchases of Treasury securities, as in QE, raise their price and lower their yields - the channels explaining this effect could be several. Krishnamurthy and Vissing-Jorgensen (2011) describe and empirically evaluate a series of plausible ones. A first channel could be "signaling" (Eggertsson and Woodford, 2003): the large quantity of long-duration assets could be viewed as a credible commitment by the central bank to keep future shortterm interest rates low even after the economy recovers. Other channels are linked to portfolio-balance theories: in order for the central bank to purchase long-term assets, their yields have to lower in order to induce investors to sell. A "duration risk" or "preferred-habitat" channel (Vayanos and Villa, 2009) argues that the purchases of long-term assets decrease the duration risk because of the presence of investors who have preferences for holding bonds with specific maturities; and the "safety" channel (Krishnamurthy and Vissing-Jorgensen, 2010) argues instead in favor of the existence of a specific clientele for long-term safe assets, which lowers their yield. Other channels are "liquidity" (increasing liquidity decreases the liquidity premium and raises yields), "default risk" and "risk premia". A final channel is that the purchases of long-term securities affect expected inflation, thus reducing real interest rates more than nominal ones. In their empirical analysis, Krishnamurthy and Vissing-Jorgensen (2011) find that the channels through which LSAP worked appear to depend on the episode; they detect a signaling effect in the first two QE episodes, which drives down all yields, as well as a safety channel, that drives down long-term bond yields, and an inflation channel, that increases inflation expectations; the first QE episode is also associated with a decrease in risk. By using a theoretical model, Bauer and Rudebusch (2014) disentangle the decrease in long-term rates during LSAP episodes into a decrease in term premia (the "portfolio balance channel") and a decrease in the expected term structure (the "signaling channel"). In their empirical analysis, Bauer and Rudebusch (2014) find evidence of a signalling effect. On the other hand, Doh (2010), Gagnon, Raskin, Remache and Sack (2011) and D'Amico and King (2013) find evidence in favor of preferred habitat theories instead. Gagnon, Raskin, Remache and Sack (2011) also argue in favor of a channel that improved market functioning and decreased liquidity premia.

The way forward guidance affects the economy is less controversial. The leading channel is a signaling one. As we discussed, forward guidance refers to announcements made by central banks about conditions that determine their future monetary policy target decisions in order to affect current economic conditions. Long-term rates, like asset prices, depend on the markets' predic- 
tion of future short-term rates, and forward guidance can change the markets' perception. For example, this can be achieved either by communicating directly information about future monetary policy, ${ }^{30}$ or by promising/allowing the inflation rate to exceed the target for some time: according to Eggertsson and Woodford (2003), a credible commitment to higher inflation reduces future short-term rates. As noted in Campbell (2013), a policymaker promising specific future actions constrains its future behavior, and hence might be costly later on, but, at the same time, if economic agents' current decisions depend on future macroeconomic outcomes, it may positively affect the current economic performance. For example, by promising low interest rates for longer than previously expected by the markets, central banks incentivate current consumption, thus expanding aggregate demand and closing the output gap. See Campbell (2013) for a stylized, theoretical New Keynesian model with a zero lower bound that formally describes how forward guidance works when short-term interest rates are close to zero. Clearly, forward guidance only has an impact if credible.

\subsection{Unconventional Monetary Policy's Effects on Out- put and Inflation: the US Evidence}

Using their shadow rate in a factor-augmented VAR model, $\mathrm{Wu}$ and Xia (2016) estimate that between July 2009 and December 2013, US unconventional monetary policy succeeded in decreasing the unemployment rate by 1 percent (which, they found, is $0.13 \%$ more stimulative than a historical average based on the Taylor rule). While Christensen and Rudebusch (2014) and Bauer and Rudebusch (2016) find that estimates of shadow rates differ depending on the model, $\mathrm{Wu}$ and Xia (2016) find that the effects on macroeconomic variables are, however, very similar across different measures of the shadow rate.

\footnotetext{
${ }^{30}$ As shown by Femina, Friedman and Sack (2013), surveys' expectations of the date of the first interest rate increase were successfully pushed backwards by forward guidance statements.
} 
Table 2. Selected Empirical Studies on the Effects of

Unconventional Monetary Policy on Low Frequency Macroeconomic Variables: GDP and Inflation

Identification Strategy

References

\begin{tabular}{ll} 
Shadow Rate & $\cdot$ Krippner (2013) \\
& $\cdot$ Christensen and Rudebusch (2014) \\
& $\cdot$ Wu and Xia (2016) \\
& $\cdot$ Bauer and Rudebusch (2016) \\
Heteroskedasticity & $\cdot$ Brunnermeier, Palia, Sastry and Sims (2018) \\
HFI / Event-study & $\cdot$ Bundick and Smith (2019) \\
External-IV & $\cdot$ Gertler and Karadi (2015) \\
Functional VAR & $\cdot$ Inoue and Rossi (2018) \\
Sign Restrictions & $\cdot$ Baumeister and Benati (2013) \\
& $\cdot$ D'Amico and King (2017) \\
\hline \hline
\end{tabular}

Notes to the table. The table lists selected empirical studies on unconventional monetary policy.

Gertler and Karadi (2015) use instead an external instruments approach. They estimate a VAR with industrial production, inflation, the one year bond rate (as a measure of the policy instrument) and the excess bond premium, using the 3-month fed funds future changes around announcement dates as the instrument. They find that a one standard deviation contractionary shock to the fed funds future increases the one year government bond rate by 25 basis points, and decreases output with a peak effect of -0.4 percent after two years. Inflation also decreases, while the excess bond premium increases by 10 basis points and remains different from zero by about 2 years. Furthermore, by taking into account financial variables' information, they find that monetary policy substantially affects credit costs. 
Using the Functional VAR approach, Inoue and Rossi (2018) find that the effects of unconventional monetary policy shocks on output and inflation are similar to those of conventional ones: an expansionary shock increases both output and inflation; the response is typically hump-shaped, and peaks a few quarters after the initial shock. Note that, in their framework, the shape of the monetary shock is different in each episode, as it is described by the specific change in the yield curve at the time of a monetary policy event. As a result, the responses are time-varying and differ depending on the monetary policy episode. In particular, for example, the response on output has a maximum effect that is between one and two percent, and some of the largest responses are associated with the first LSAP announcement.

Bundick and Smith (2019) instead take a HFI approach, using directly the HFI shock in a VAR. They estimate a VAR that includes monthly measures of real GDP, real investment, capacity utilization, inflation, the path factor shock and the two-year Treasury yield, using a recursive identification with this order. They find that forward guidance shocks increase output, with a peak effect of 1.5 basis points following a 6 basis point decline in the path factor; they also increase investment and capacity utilization, and modestly inflation.

Using a heteroskedasticity-based identification approach, Brunnermeier, Palia, Sastry and Sims (2018) find that monetary policy shocks increase the interbank spread in a long sample that includes conventional and unconventional periods; they also find that shocks in financial markets affect the macroeconomy.

Earlier studies focus on traditional approaches with sign restrictions. When using sign restrictions, researchers often need to pool information from both conventional and unconventional monetary policy regimes to increase the sample size needed for estimation. Hence, taking into account timevariation becomes an important issue. Baumeister and Benati (2013) focus on a time-varying VAR with sign-restrictions estimated during both periods of conventional monetary policy and the zero lower bound. They find that, in conventional times, an increase of 25 basis points in the fed funds rate decreases inflation between -0.3 and -0.4 in 1970-1990 but the effect is larger in magnitude in the 2000s, reaching estimates between -1 and -1.5. A similar finding holds for output growth: the effect is around -1 before 2000 and be- 
comes -2 or -3 after then. ${ }^{31}$ Similarly, Debortoli, Gali and Gambetti (2019) estimate a time-varying structural VAR identified using sign and long-run restrictions and find empirical evidence that, by using unconventional monetary policies, the central bank successfully steered rates in a way similar to normal times, thus resulting in similar responses of output and inflation - the so-called "irrelevance hypothesis" (that is, whether the economy is or not at the zero lower bound is irrelevant for the effectiveness of monetary policy). ${ }^{32}$ D'Amico and King (2017) use sign-restrictions to identify shocks to "anticipated" monetary policy, that is, news about future monetary policy induced by credible forward guidance. They find that forward guidance has large and persistent effects on inflation and real activity, with a magnitude that is larger than typical unanticipated monetary policy shocks.

\subsection{Exchange Rates, Capital Flows and the Interna- tional Evidence}

Unconventional monetary policies have been implemented in countries other than the US: for a historical description of similar programs in Europe, the UK and Japan, see Rogers, Scotti and Wright (2014) and Gagnon and Sack (2018). ${ }^{33}$ In their survey, Hartmann and Smets (2018) provide an overview of the European Central Bank (ECB) monetary policy since its start, and describe the unconventional monetary policies that it followed during the financial crisis.

Estimated effects on asset prices in countries other than the US. In terms of empirical results, broadly speaking, a variety of studies have found that they are similar to those for the US. Most of the studies use a high-frequency approach based on announcements. For example, Rogers, Scotti and Wright (2014) identify monetary policy shocks in two principal components estimated from a cross-section of bond yields, stock prices and exchange rates in a short window of time around monetary policy announcements in the

\footnotetext{
${ }^{31}$ Using a more structural model, Kulish, Morley and Robinson (2017) find that an exogenous change in the expected duration of the ZLB has significant effects on the real economy. In addition, there is considerable variation in the expected duration of the ZLB over time; for example, it increased in 2011 as the US monetary authority moved to calendar-based forward guidance.

${ }^{32}$ Using a different methodology, Ikeda, Li, Mavroeidis and Zanetti (2020) find instead that monetary policy is indeed constrained at the zero lower bound.

${ }^{33}$ Gagnon and Sack (2018) also consider Sweden.
} 
US, the UK, the euro area and Japan. They also verify the robustness of their findings to a heteroskedasticity-based approach, assuming the variance of policy shocks increases on days of monetary policy announcements. They find that unconventional policies have been effective in improving financial conditions by lowering government bond yields and reducing risk premia. The pass-through from bond yields to other asset prices has been bigger for the US than for other countries. They also find evidence of spillovers across countries - the US affecting more the rest of the world (UK, Europe and Japan) than vice-versa. Gagnon, Raskin, Remache and Sack (2011) find that, in Japan and the UK, LSAP had similar effects on asset prices as in the US, and Joyce and Tong (2012) also note that LSAP led to a decrease in long-term yields in the UK. Wang and Mayes (2012) analyze the effects of monetary policy announcements in New Zealand, Australia, the UK and Europe on their country-specific aggregate stock prices and find a significant negative reaction. Interestingly, for countries at the zero lower bound, such as the UK and the euro area, the effect becomes positive. Thus, they conclude that, while there are many similarities between the US experience and that of other countries, there are also some differences, depending on whether the countries hit or not the zero lower bound. Using external-IV, Altavilla, Canova and Ciccarelli (2019) study how monetary policy passes through to lending rates to households and firms in the euro area using a bank-level detailed dataset and find that non-standard measures reduce lending rate heterogeneity. Von Borstel, Eickmeier and Krippner (2016) consider several identification schemes, including shadow rates, to study the effect of monetary policy on bank lending rates in the euro area, and find that it has not changed in unconventional times relative to conventional ones.

Other papers perform event studies on asset purchases, not just announcements. For example, Meaning and Zhu (2011) focus on the UK experience using the methodology in D'Amico and King (2013), and conclude that the Bank of England LSAP programs successfully lowered bond yields, while Ghysels, Idier, Manganelli and Vergote (2017) use high-frequency data on purchases by the ECB, and find that the interventions were effective in decreasing government bond yields in the euro area as well. Similarly, Joyce and Tong (2012) study local supply effects in the UK using high-frequency data on both announcements as well as actual purchases, obtaining similar results - interestingly, they find that it takes time for the financial market reactions to be fully priced in after an announcement. 
Table 3. Selected Empirical Studies on the Effects of Unconventional Monetary Policy: The International Evidence

Identification Strategy

References

Shadow Rate

- Von Borstel, Eickmeier and Krippner (2016)

- Wu and Xia (2018)

Heteroskedasticity · Rogers, Scotti and Wright (2014)

- Bowman, Londono and Sapriza (2015)

HFI / Event-study · Gagnon, Raskin, Ramache and Sack (2011)

- Joyce, Lasaosa, Stevens and Tong (2011)

- Meaning and Zhu (2011)

- Christensen and Rudebusch (2012)

- Joyce and Tong (2012)

- Wang and Meyes (2012)

- Rogers, Scotti and Wright (2014)

- Glick and Leduc (2015)

- Neely (2015)

- Bluwstein and Canova (2016)

- Ghysels, Idier, Manganelli and Vergote (2017)

- Fratzscher, Lo Duca and Straub (2018)

External-IV · Rogers, Scotti and Wright (2018)

- Miranda Agrippino and Rey (2020)

- Altavilla, Canova and Ciccarelli (2019)

Functional VAR · Inoue and Rossi (2019)

Sign Restrictions $\quad$ Kapetanios, Haroon, Stevens and Theodoridis (2012)

- Gambacorta, Hofmann and Peersman (2014)

- Hausman and Wieland (2014)

- Weale and Wieladek (2016)

· Boeckx, Dossche and Peersman (2017)

Notes to the table. The table lists selected empirical studies on unconventional 
monetary policy.

The effects of US unconventional policies on international markets. One strand of the literature studies the effects on exchange rates. Conventional monetary policy typically appreciates the currency of the country implementing an expansionary move (Clarida and Gali, 1994; Eichenbaum and Evans, 1995). Using a VAR with external instruments, Rogers, Scotti and Wright (2018) estimate the effects of unconventional monetary policy on exchange rates and foreign risk premia; they find that a monetary policy easing lowers domestic and foreign risk term premia and depreciates the domestic currency. Using a HFI/event-study approach, Neely (2015) also finds that US unconventional monetary policy announcements decrease the spot value of the US dollar as well as international long-term bond yields; the impact depreciation effect is similar to that observed in conventional times. The result that the effects of monetary policy on exchange rates are similar in the conventional and unconventional periods seems very robust - see also Bhattarai and Neely's (2017) literature review. Glick and Leduc (2015) distinguish between shocks to three different assets around monetary policy announcements: the fed funds rate, the one-year ahead eurodollar future rate; and the first principal component from a set of long-term Treasury rate futures. They find that monetary policy is effective in both conventional and unconventional times; however, the US dollar depreciates only in response to the first shock in conventional times, while it also depreciates in response to the other shocks in unconventional times. Similarly, using the Functional VAR, Inoue and Rossi (2019) show that a monetary policy easing leads to a depreciation of the country's spot nominal exchange rate in both conventional and unconventional periods; however, there is substantial heterogeneity in monetary policy shocks over time and their effects depend on the way they affect agents' expectations. For example, shocks that are fully contractionary (expansionary) lead to that country's exchange rate depreciation (appreciation); however, shocks that are contractionary at the short-end of the yield curve and expansionary on the long-end may either appreciate or depreciate the exchange rate. Finally, monetary policy operates by affecting real interest rates, not just inflation expectations. ${ }^{34}$

Another strand of the literature investigates spillovers of monetary pol-

\footnotetext{
${ }^{34}$ Gali' (2018) finds that financial markets' expectations of interest rate differentials in the near (distant) future have empirically larger (smaller) effects than implied by theory, an empirical finding that he refers to as "the forward guidance exchange rate puzzle".
} 
icy across foreign financial markets. Using a HFI approach, Rogers, Scotti and Wright (2014) find that a monetary policy easing in countries other than the US appreciates the US dollar and may, in some cases, cause longerterm US interest rates to fall. Using a heteroskedasticity-based identification approach, Bowman, Londono and Sapriza (2015) find spillover effects of US unconventional monetary policy to sovereign yields in emerging markets; the effects depend on country-specific characteristics. Other studies have investigated the spillovers of US unconventional monetary policy on capital flows. Using an external IV approach, Miranda-Agrippino and Rey (2020) find that US monetary policy induces co-movements in international financial variables: an expansionary shock significantly increases a global factor that explains a sizeable share of the variation in world risky assets and leads to a decrease in risk aversion in global financial markets. Using a HFI/event-study approach that includes announcements as well as actual purchases of Treasury bonds and other liquidity operations, Fratzscher, Lo Duca and Straub (2018) investigate the international spillovers of US quantitative easing policies. They find that QE1 and liquidity operations caused a portfolio rebalancing effect with capital flows towards US equity funds, while the remaining QE announcements and Treasury purchases caused inflows into emerging markets.

The effects of international unconventional policies on macroeconomic variables, such as output and inflation. A widespread approach to identification in this literature involves sign restrictions: Kapetanios, Haroon, Stevens and Theodoridis (2012) estimate a 1.5\% peak effect on real GDP from the first QE announcement in the UK, and a $1.25 \%$ effect on annual CPI inflation. The estimates are obtained by a counterfactual time-varying VAR analysis, where QE purchases are assumed to reduce long-term UK government bond yields by 100 basis points. Similarly, using a VAR with recursive and sign-restrictions, Weale and Wieladek (2016) find that announcements of asset purchases increase both output and inflation in the UK and the US. A similar analysis was done for Japan by Hausman and Wieland (2014). ${ }^{35}$ Some papers focus on balance sheets as the instrument of monetary policy: Gambacorta, Hofmann and Peersman (2014) use a panel VAR with eight countries, while Boeckx, Dossche and Peersman (2017) focus on the ECB; they both find that unconventional monetary policy increases output and inflation. Altavilla, Giannone and Lenza (2016) use a HFI/event-study approach

\footnotetext{
${ }^{35}$ Hayashi and Koeda (2019) use a regime switching Structural VAR approach for Japan.
} 
to study the effects of unconventional monetary policy on macro variables in European countries. They perform a two-step procedure; first, they identify an unconventional monetary policy shock in high frequency data using an event-study to estimate the decrease in bond yields due to a policy intervention. Then, they estimate a VAR model with both macro and financial variables, including bond yields, assuming that the relationship among the variables remained constant during the crisis; under the assumption that the coefficients are stable, they perform counterfactual analysis to estimate the effect of the calibrated decrease in bond yields on the macroeconomic variables and find an increase in output, credit and prices. Bluwstein and Canova (2016) use a mixed-frequency, time-varying VAR with announcements and timing restrictions to study the effects of unconventional policies on European countries that did not adopt the euro; they find sizeable spillovers of unconventional monetary policy, especially on inflation.

Which channels at work? Christensen and Rudebusch (2012) find that, while the signaling channel was important for the US, the portfolio balance one was the most important for the UK; a finding also supported by Joyce, Lasaosa, Stevens and Tong (2011).

\subsection{The Effects on Survey Expectations}

Section 3.1 reviewed the literature on how unconventional monetary policy shocks affect asset prices via influencing financial market expectations. More generally, it is interesting to study how monetary policy affects every kind of expectations. When measuring the effects of monetary policy on survey expectations, one encounters a series of potential problems. One issue is that survey expectations are measured at points in time that are not necessarily the days in which a monetary policy announcement is made: if changes in survey expectations are affected by other shocks, this may make the identification problematic. To mitigate the problem, one can include control variables in the regression in an attempt to control for changes in expectations that are due to other news and shocks and make sure that all the necessary control variables are included. Under market efficiency, monetary policy shocks should be uncorrelated with any other shock revealed contemporaneously or before, so omitting the latter shocks would be inconsequential. On the other hand, omitting data realized after the monetary policy shock which update forecasters' expectations is inconsequential only if the latter are uncorrelated with the monetary policy shock; this crucially depends on 
the forecasts being rational. In addition, the monetary policy shock needs to be exogenous, in the sense that central banks should not react to survey expectations when setting their policies; this can be achieved by judiciously matching the time of the survey with the time of the monetary policy shock. Finally, the control variables themselves should not be affected by the policy; this implies that, if one controls for news announcements of GDP growth or inflation (such as forecast revisions of GDP growth or inflation), the latter capture the effect of omitted variables, but not the effects of the monetary policy shock itself.

Based on a HFI/event-study approach, Campbell, Evans, Fisher and Justiniano (2012) find that expansionary forward guidance shocks may decrease unemployment survey expectations; see also Del Negro, Giannoni and Patterson (2015) for similar findings. Since this is contrary to how we expect the economy should react to monetary policy shocks, this finding is often interpreted as empirical evidence that announcements reveal bad news about the state of the economy - under the assumption that the central bank has an informational advantage on the private sector - and are not true monetary policy shocks. Campbell, Fisher, Justiniano and Melosi (2017) argue that the puzzling result can, in fact, be attributed to informational effects. They use forward guidance shocks constructed as the difference between the central bank's and the private sector's forecasts, which capture the extra information that the central bank has relative to private participants. They consider two measures: the first is based on the nowcast, and the second is a long- (one-year-ahead-) horizon one. They show that, in a regression of the change in the policy rate on monetary policy dates on the one-year-ahead new measure, the coefficient is significant and negative. ${ }^{36}$ Hoetsch, Rossi and Sekhposyan (2019) find that the results may depend on the sample period.

Focusing on the effects of unconventional monetary policy shocks on asset price surveys, Altavilla and Giannone (2017) find that professional forecasters predict bond yields to drop significantly for at least one year after accommodative monetary policy announcements.

Survey data can also be used to identify the shock. Darracq-Paries and De Santis (2015) use survey data on bank lending in a panel VAR of several euro area countries to study the effects of an expansionary credit supply

\footnotetext{
${ }^{36}$ They also show that a large portion of the variability in policy rates remains unexplained by their informational-effect factor, so it is still possible that forward guidance successfully affects market expectations. Similar results are obtained by Andrade and Ferroni (2019) for euro area data.
} 
shock intended to increase liquidity in financial markets by increasing the availability and decreasing the cost of external finance to bank, households and non-financial organizations. The shock is identified using sign restrictions. In counterfactual simulations, they find that three year long-term refinancing operations in the euro area increased real GDP and prices.

Table 4. Selected Empirical Studies on the Effects of Unconventional Monetary Policy Shocks on Low Frequency Macroeconomic Variables: Survey Expectations

\begin{tabular}{ll}
\hline \hline Identification Strategy & \\
\hline Shadow Rate & $\cdot \mathrm{N} / \mathrm{A}$ \\
Heteroskedasticity & $\cdot \mathrm{N} / \mathrm{A}$ \\
HFI / Event-study & $\cdot$ Campbell, Evans, Fisher and Justiniano (2012) \\
& $\cdot$ Del Negro, Giannoni and Patterson (2015) \\
& $\cdot$ Altavilla and Giannone (2017) \\
& $\cdot$ Campbell, Fisher, Justiniano and Melosi (2017) \\
External-IV & $\cdot \mathrm{N} / \mathrm{A}$ \\
Functional VAR & $\cdot \mathrm{N} / \mathrm{A}$ \\
Sign Restrictions & $\cdot$ Darracq-Paries and De Santis (2015) \\
\hline \hline
\end{tabular}

Notes to the table. The table lists selected empirical studies on unconventional monetary policy. 


\section{Conclusions}

Economists predict that the zero lower bound will occur more and more often in the future. Traditional econometric techniques that identify and estimate the effects of monetary policy face the problem of merging datasets from periods when conventional identification was feasible with periods at the zero lower bound, where the conventional approach fails. Thus, the need for alternative identification schemes, which we have reviewed and which are part of a promising and currently active area of research in econometrics. In addition, as we have argued, such techniques can also be useful outside the zero lower bound and, hence, may also have an important place in the central banks' conventional toolbox.

\section{References}

Altavilla, C., F. Canova and M. Ciccarelli (2019), "Mending the Broken Link: Heterogeneous Bank Lending Rates and Monetary Policy PassThrough, Journal of Monetary Economics, forthcoming.

Altavilla, C. and D. Giannone (2017), "The Effectiveness of Non-Standard Monetary Policy Measures: Evidence from Survey Data", Journal of Applied Econometrics 32(5), 952-964.

Altavilla, C., D. Giannone and M. Lenza (2016), "The Financial and Macroeconomic Effects of the OMT Announcements," International Journal of Central Banking 12(3), 29-57.

Andrade, P. and F. Ferroni (2019), "Delphic and Odyssean Monetary Policy Shocks: Evidence from the Euro-Area", mimeo.

Ball, Ray (2017), "The Fama Portfolio: Selected Papers of Eugene F. Fama", Chap, Fama, Fisher, Jensen and Roll (1969): Retrospective Comments, edited by John H. Cochrane and Tobias J. Moskowitz, University of Chicago Press.

Bauer, M.D. and G.D. Rudebusch (2014), "The Signalling Channel for Federal Reserve Bond Purchases?, International Journal of Central Banking 10(3), 233-289.

Bauer, M.D. and G.D. Rudebusch (2016), "Monetary Policy Expectations at the Zero Lower Bound," Journal of Money, Credit and Banking 48(7),1439-1465. 
Baumeister, C. and L. Benati (2013), "Unconventional Monetary Policy and the Great Recession: Estimating the Macroeconomic Effects of a Spread Compression at the Zero Lower Bound", International Journal of Central Banking 9(2), 165-212.

Bernanke, B. and K. Kuttner (2005), "What Explains the Stock Market's Reaction to Federal Reserve Policy?", Journal of Finance 60(3), 1221-1257.

Bhattarai, S. and C.J. Neely (2017), "An Analysis of the Literature on International Unconventional Monetary Policy", Journal of Economic Literature, forthcoming.

Bluwstein, K. and F. Canova (2016), "Beggar-Thy-Neighbor? The International Effects of ECB Unconventional Monetary Policy Measures", International Journal of Central Banking 12-3.

Boeckx, J., M. Dossche and G. Peersman (2017), "Effectiveness and Transmission of the ECB's Balance Sheet Policies", International Journal of Central Banking 13(1) 297-333.

Borio, C. and A. Zabai (2016), "Unconventional Monetary Policies: a Re-Appraisal", Bank for International Settlements Working Paper.

Bowman, D., J.M. Londono and H. Sapriza (2015), "U.S. Unconventional Monetary Policy and Transmission to Emerging Market Economies", Journal of International Money and Finance 55(C), 27-59.

Brunnermeier, M., D. Palia, K.A. Sastry and C. Sims (2018), "Feedbacks: Financial Markets and Economic Activity", mimeo, Princeton University.

Bundick, B. and A.L. Smith (2015), "The Dynamic Effects of Forward Guidance Shocks", Review of Economics and Statistics, forthcoming.

Cahill, M.E., S. D'Amico, C. Li and J.S. Sears (2013), "Duration Risk versus Local Supply Channel in Treasury Yields: Evidence from the Federal Reserve's Asset Purchase Announcements", Federal Reserve Board Finance and Economics Discussion Series No. 2013-35.

Cai, M., M. Del Negro, M. Giannoni, A. Gupta, P. Li and E. Moszkowski (2018), "DSGE Forecasts of the Lost Recovery", Federal Reserve Bank of New York Staff Report 844.

Campbell, J.R. (2013), "Odyssean Forward Guidance in Monetary Policy: A Primer". In W. DenHaan (ed.), Forward Guidance: Perspectives from Central Bankers, Scholars and Market Participants, 87-105, CEPR.

Campbell, J.R., C.L. Evans, J.D.M. Fisher and A. Justiniano (2012), "Macroeconomic Effects of Federal Reserve Forward Guidance", Brookings Papers on Economic Activity 43(1), 1-80. 
Campbell, J.R., J.D.M. Fisher, A. Justiniano and L. Melosi (2017), "Forward Guidance and Macroeconomic Outcomes since the Financial Crisis", NBER Macroeconomics Annual, 283-357.

Canova, F. and G. De Nicolo (2002), "Monetary Disturbances Matter for Business Fluctuations in the G-7", Journal of Monetary Economics 49(6), 1131-1159.

Chen, Q., A. Filardo, D. He and F. Zhu (2016), "Financial Crisis, U.S. Unconventional Monetary Policy and International Spillovers", Journal of International Money and Finance 67, 62-81.

Christensen, J.H.E. and G.D. Rudebusch (2012), "The Response of Interest Rates to US and UK Quantitative Easing", The Economic Journal 122(564), F385-F414,

Christensen, J.H.E. and G.D. Rudebusch (2014), "Estimating Shadowrate Term Structure Models with Near-zero Yields," Journal of Financial Econometrics, 1-34.

Christiano, L.J., M. Eichenbaum and C.L. Evans (1999), "Monetary Policy Shocks: What Have We Learned and to What End?", in: J. B. Taylor and M. Woodford (ed.), Handbook of Macroeconomics1 Vol. 1, Chapter 2, $65-148$.

Chung, H., J.P. Laforte, D. Reifschneider and J.C. Williams (2012), "Have We Underestimated the Likelihood and Severity of Zero Lower Bound Events?", Journal of Money, Credit and Banking 44, 47-82.

Clarida, R. and J. Gali' (1994). "Sources of Real Exchange Rate Fluctuations: How Important Are Nominal Shocks?", Carnegie Rochester Conference Series on Public Policy 41, 1-56.

Darracq-Paries, M. and R.A. De Santis (2015), "A Non-Standard Monetary Policy Shock: The ECB's 3-Year LTROs and the Shift in Credit Supply", Journal of International Money and Finance 54(6), 1-34.

D'Amico, S. and T.B. King (2013), "Flow and Stock Effects of Large-Scale Treasury Purchases", Journal of Financial Economics 108, 425-448.

D'Amico, S. and T.B. King (2017), "What Does Anticipated Monetary Policy Do?", Federal Reserve Bank of Chicago Working Paper 2015-10.

Debortoli, D., J. Gali and L. Gambetti (2019), "On the Empirical (Ir)Relevance of the Zero Lower Bound Constraint", NBER Working Paper w25820.

Del Negro, M., M. Giannoni and C. Patterson (2015), "The Forward Guidance Puzzle," Federal Reserve Bank of New York Staff Reports No. 574.

Del Negro, M., D. Giannone, M. Giannoni and A. Tambalotti (2018), "Global Trends in Interest Rates and r*", mimeo, Federal Reserve Bank of 
New York.

Diebold, F.X. and C. Li (2006), "Forecasting the Term Structure of Government Bond Yields", Journal of Econometrics 130(2), 337-364.

Doh, T. (2010), "The Efficacy of Large-Scale Asset Purchases at the Zero Lower Bound," Federal Reserve Bank of Kansas City Economic Review 2, 5-34.

Eggertsson, G. and M. Woodford (2003), "The Zero Lower Bound on Interest Rates and Optimal Monetary Policy", Brookings Papers on Economic Activity 1, 139-211.

Eichenbaum, M. and C. Evans (1995), "Some Empirical Evidence on the Effects of Monetary Policy Shocks on Exchange Rates," Quarterly Journal of Economics 1-22.

Fama, E.F., L. Fisher, M.C. Jensen and R. Roll (1969), "The Adjustment of Stock Prices to New Information", International Economic Review 10(1) $1-21$.

Faust, J. (1998), "The Robustness of Identified VAR Conclusions about Money," Carnegie-Rochester Conference Series on Public Policy 49(1), 207244.

Femina, K., S. Friedman and B. Sack (2013), "The Effects of Policy Guidance on Perceptions of the Fed's Reaction Function", Federal Reserve Bank of New York Staff Report No. 652.

Fratzscher, M., M. Lo Duca and R. Straub (2018), "On the International Spillovers of US Quantitative Easing", Economic Journal 128(608), 330-77.

Gagnon, J., M. Raskin, J. Remache, and B.P. Sack (2011), "The Financial Market Effects of the Federal Reserve's Large-Scale Asset Purchases", International Journal of Central Banking 7(1), pp. 3-43.

Gagnon, J. and B. Sack (2018), "QE: A User's Guide", PIIE Working Paper No. 18-19.

Gali', J. (2018), "Forward Guidance and the Exchange Rate," Barcelona GSE Working Paper n. 1021.

Gambacorta, L., B. Hofmann and G. Peersman (2014), "The Effectiveness of Unconventional Monetary Policy at the Zero Lower Bound: A CrossCountry Analysis", Journal of Money, Credit and Banking 46(4), 615-42.

Ganics, G., A. Inoue and B. Rossi (2018), "Confidence Intervals for the Bias and Size Distortion in IV and Local-Projections-IV Models", mimeo.

Gertler, M. and P. Karadi (2015), "Monetary Policy Surprises, Credit Costs and Economic Activity", American Economic Journal: Macroeconomics, American Economic Association 7(1), 44-76. 
Ghysels, E., J. Idier, S. Manganelli and O. Vergote (2017), "A High Frequency Assessment of the ECB Securities Markets Programme," Journal of the European Economic Association 15(1), 218-243.

Gilchrist, S., D. Lopez-Salido and E. Zakrajsek (2015), "Monetary Policy and Real Borrowing Costs at the Zero Lower Bound", American Economic Journal: Macroeconomics 7(1): 77-109.

Glick, R. and S. Leduc (2015), "Unconventional Monetary Policy and the Dollar: Conventional Signs, Unconventional Magnitudes", Federal Reserve Bank of San Francisco W.P. 2015-18.

Greenlaw, D., J.D. Hamilton, E. Harris and K.D. West (2018), "A Skeptical View of the Impact of the Fed's Balance Sheet", NBER Working Paper No. 24687.

Gürkaynak, R.S., B. Sack and E. Swanson (2005), "Do Actions Speak Louder Than Words? The Response of Asset Prices to Monetary Policy Actions and Statements", International Journal of Central Banking 1(1),5593.

Hamilton, J.D. and J.C. Wu (2012), "The Effectiveness of Alternative Monetary Policy Tools in a Zero Lower Bound Environment", Journal of Money, Credit and Banking 44(1, Suppl.), 3-46.

Hanson, S.G. and J.C. Stein (2015), "Monetary Policy and Long-Term Real Rates", Journal of Financial Economics 115(3), 429-448.

Hartmann, P. and F. Smets (2018), "The First 20 Years of the European Central Bank: Monetary Policy", Brooking Papers on Economic Activity, forthcoming.

Hausman, J.K. and J.F. Wieland (2014): "Abenomics: Preliminary Analysis and Outlook", Brookings Papers on Economic Activity 48(1), 1-76.

Hayashi, F. (2001), Econometrics, Princeton University Press.

Hayashi, F., and J. Koeda (2019), "Exiting from QE", Quantitative Economics, forthcoming.

Hoetsch, L., B. Rossi and T. Sekhposyan (2019), "Is the Information Channel Important? New Empirical Evidence", mimeo.

Ichiue, H. and Y. Ueno (2013), "Estimating Term Premia at the Zero Bound: an Analysis of Japanese, US, and UK Yields", Bank of Japan Working Paper 13-E-8.

Ikeda, D., S. Li, S. Mavroeidis and F. Zanetti (2020), "Econometric Analysis of Monetary Policy at the Zero Lower Bound", mimeo.

Inoue, A. and B. Rossi (2018), "A New Approach to Measuring Economic Policy Shocks, with an Application to Conventional and Unconven- 
tional Monetary Policy", mimeo.

Inoue, A. and B. Rossi (2019), "The Effects of Conventional and Unconventional Monetary Policy on Exchange Rates", mimeo.

Jarociński, M. and P. Karadi (2018), "Deconstructing Monetary Policy Surprises: the Role of Information Shocks," European Central Bank Working Paper Series 2133.

Johannsen, B.K. and E. Mertens (2018), "A Time Series Model of Interest Rates With the Effective Lower Bound", mimeo, Federal Reserve Board.

Jordà, Ò. (2005), "Estimation and Inference of Impulse Responses by Local Projections," American Economic Review 95(1), 161-182.

Jordà, Ò. (2019), "Local Projections: New Developments", mimeo.

Joyce, M.A.S., A. Lasaosa, I. Stevens and M. Tong (2011), "The Financial Market Impact of Quantitative Easing in the United Kingdom", International Journal of Central Banking 7(3), 113-62.

Joyce, M., D. Miles, A. Scott and D. Vayanos (2012), "Quantitative Easing and Unconventional Monetary Policy: An Introduction", Economic Journal 122(564), F271-F288.

Joyce, M. and M. Tong (2012), "QE and the Gilt Market: a Disaggregated Analysis", Economic Journal 122, 348-384.

Kapetanios, G., M. Haroon, I. Stevens and K. Theodoridis (2012): "Assessing the Economy-Wide Effects of Quantitative Easing," Economic Journal 122(564), F316-F347.

Kilian, L. and H. Lütkepohl (2017), Structural Vector Autoregressive Analysis. Cambridge University Press.

Kim, D.H. and K.J. Singleton (2012), "Term Structure Models and the Zero Bound: an Empirical Investigation of Japanese Yields," Journal of Econometrics 170, 32-49.

Kocherlakota, N. (2018), "The Future of the Zero Lower Bound Problem", Journal of International Money and Finance, forthcoming.

Kortela, T. (2016), "A Shadow Rate Model with Time-varying Lower Bound of Interest Rates", Bank of Finland Research Discussion Paper 19/2016.

Krippner, L. (2013a), "A Tractable Framework for Zero Lower Bound Gaussian Term Structure Models," Australian National University CAMA Working Paper 49/2013.

Krippner, L. (2013b), "Measuring the Stance of Monetary Policy in Zero Lower Bound Environments", Economics Letters 118, 135-138.

Krippner, L. (2016), "Documentation for Measures of Monetary Policy", mimeo, Reserve Bank of New Zealand. 
Krishnamurthy, A. and A. Vissing-Jorgensen (2010), "The Aggregate Demand for Treasury Debt", Journal of Political Economy 120(2), 233-267.

Krishnamurthy, A. and A. Vissing-Jorgensen (2011), "The Effects of Quantitative Easing on Interest Rates: Channels and Policy Implications", Brookings Papers on Economic Activity 2, pp. 215-65.

Kulish, M., J. Morley and T. Robinson (2017), "Estimating DSGE Models with Zero Interest Rate Policy", Journal of Monetary Economics 88, 35-49.

Kuo, C.H., A. Inoue and B. Rossi (2019), "Identifying the Sources of Model Misspecification", Journal of Monetary Economics, forthcoming.

Kuttner, K.N. (2001), "Monetary Policy Surprises and Interest Rates: Evidence From the Fed Funds Futures Market," Journal of Monetary Economics $47(3), 523-544$.

Kuttner, K.N. (2018), "Outside the Box: Unconventional Monetary Policy in the Great Recession and Beyond", Brookings Center of Economic Research.

Laubach, T. and J. Williams (2003), "Measuring the Natural Rate of Interest", The Review of Economics and Statistics - Notes, 85(4), 1063-1070.

Lemke, W. and A. Vladu (2017), "Below the Zero Lower Bound: A Shadow-rate Term Structure Model for the Euro Area," ECB Working Paper No. 1991.

Lombardi, M. and F. Zhu (2014), "A Shadow Policy Rate to Calibrate US Monetary Policy at the Zero Lower Bound", BIS Working Paper No. 452.

Mavroeidis, S. (2020), "Identification at the Zero Lower Bound", mimeo.

Meaning, J. and F. Zhu (2011), "The Impact of Recent Central Bank Asset Purchase Programmes," BIS Quarterly Review, 73-83.

Mertens, E. and B. Johanssen (2018), "A Time Series Model of Interest Rates With the Effective Lower Bound", Federal Reserve Board Finance and Economics Discussion Series No. 2016-033.

Miranda-Agrippino, S. (2016), "Unsurprising Shocks: Information, Premia and the Monetary Transmission", Centre for Macroeconomics Discussion Paper 2016-013.

Miranda-Agrippino, S. and H. Rey (2020), "U.S. Monetary Policy and the Global Financial Cycle", Review of Economic Studies, forthcoming.

Miranda-Agrippino, S. and G. Ricco (2018), "The Transmission of Monetary Policy Shocks", Journal of Monetary Economics, forthcoming.

Montiel Olea, J.L. and Pflueger, C. (2013), "A Robust Test for Weak Instruments", Journal of Business \& Economic Statistics 31(3), 358-369. 
Montiel Olea, J.L., J.H. Stock and M.W. Watson (2012), "Inference in Structural VARs with External Instruments", mimeo.

Neely, C.J. (2015), "Unconventional Monetary Policy Had Large International Effects," Journal of Banking 65 Finance 52(C), 101-111.

Nelson, C.R. and A.F. Siegel (1987), "Parsimonious Modeling of Yield Curve", Journal of Business 60, 473-489.

Piazzesi, M. and E.T. Swanson (2008), "Futures Prices as Risk-Adjusted Forecasts of Monetary Policy", Journal of Monetary Economics 55(4), 677691.

Reichlin, L. (2011), "Comment on: Let's Twist Again: A High-Frequency Event-Study Analysis of Operation Twist and Its Implications for QE2", Brookings Papers on Economic Activity, 189-195.

Rigobon, R. (2003), "Identification through Heteroskedasticity", Review of Economics and Statistics 85, 777-92.

Rogers, J., C, Scotti and J.H. Wright (2014), "Evaluating Asset-Market Effects of Unconventional Monetary Policy: A Multi-Country Review," Economic Policy 29, 3-50.

Rogers, J., C. Scotti and J.H. Wright (2016), "Unconventional Monetary Policy and International Risk Premia", Board of Governors IFD Papers No. 1172.

Romer C.D. and D.H. Romer (2000), "Federal Reserve Information and the Behavior of Interest Rates", American Economic Review 90(3), 429-457.

Romer, C. and D. Romer (2004), "A New Measure of Monetary Shocks: Derivation and Implications," American Economic Review 94(4), 1055-1084.

Rossi, B. and T. Sekhposyan (2016), "Forecast Rationality Tests in the Presence of Instabilities, With Applications to Federal Reserve and Survey Forecasts", Journal of Applied Econometrics 31(3), 507-532.

Sims, C. (1980), "Macroeconomics and Reality", Econometrica 48(1), 148.

Stock, J.H. and M.W. Watson (2001), "Vector Autoregressions," Journal of Economic Perspectives 15(4), 101-115.

Stock, J.H. and M.W. Watson (2018), "Identification and Estimation of Dynamic Causal Effects in Macroeconomics Using External Instruments", Economic Journal 128, 917-948.

Stock, J.H., J.H. Wright and M. Yogo (2002), "A Survey of Weak Instruments and Weak Identification in Generalized Method of Moments", Journal of Business \& Economic Statistics 20(4), 518-529. 
Stock, J.H., and M. Yogo (2005), "Testing for Weak Instruments in Linear IV Regression," in: Andrews, D.W.K. (ed.), Identification and Inference for Econometric Models. New York: Cambridge University Press, 80-108.

Swanson, E. (2011), "Let's Twist Again: A High-Frequency Event-Study Analysis of Operation Twist and Its Implications for QE2", Brookings Papers on Economic Activity, 151-188.

Swanson, E. (2017), "Measuring the Effects of Federal Reserve Forward Guidance and Asset Purchases on Financial Markets", UC Irvine, mimeo.

Uhlig, H. (2005), "What Are the Effects of Monetary Policy on Output? Results from an Agnostic Identification Procedure", Journal of Monetary Economics 52(2), 381-419.

Von Borstel, J., S. Eickmeier and L. Krippner (2016), "The Interest Rate Pass-Through in the Euro Area during the Sovereign Debt Crisis", Journal of International Money and Finance 68, 386-402.

Walentin, K. (2014), "Business Cycle Implications of Mortgage Spreads", Journal of Monetary Economics 67, 62-77.

Wang, S. and D. Mayes (2012), "Monetary Policy Announcements and Stock Reactions: An International Comparison", North American Journal of Economics and Finance 23(2), 145-164.

Watson, M.W. (1994), "Vector Autoregressions and Cointegration", in: R.F. Engle and D. McFadden (eds.), Handbook of Econometrics, Vol. 4, North Holland.

Weale, M. and T. Wieladek (2016), "What Are the Macroeconomic Effects of Asset Purchases?", Journal of Monetary Economics 79, 81-93.

Wright, J.H. (2012), "What does Monetary Policy do to Long-term Interest Rates at the Zero Lower Bound?", Economic Journal 122, F447-F466.

Wu, C. and F.D. Xia (2016), "Measuring the Macroeconomic Impact of Monetary Policy at the Zero Lower Bound", Journal of Money, Credit and Banking 48(2-3), 253-291.

Wu, C. and F. Xia (2018), Negative Interest Rate Policy and Yield Curve, Bank of International Settlements Working Paper No. 703.

Wu, C. and J. Zhang (2017), "A Shadow Rate New Keynesian Model", NBER Working Paper No. 22856. 


\section{Figures}

Figure 1

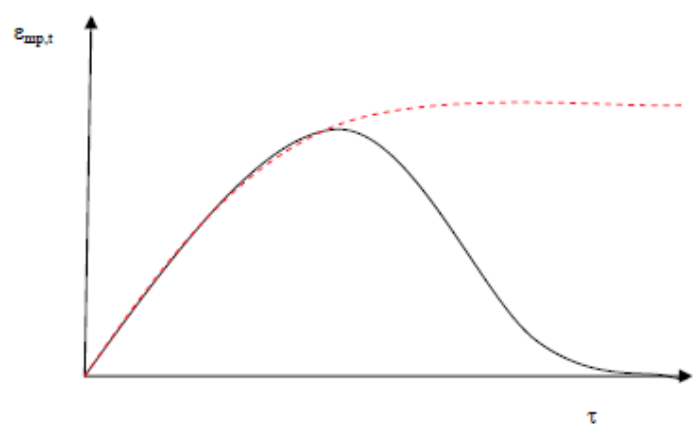

Notes to the figure. The figure plots two alternative functional monetary policy shocks $\left(\varepsilon_{m p, t}().\right)$ as a function of the maturity $\tau$. 


\title{
Not-for-Publication Appendix to: \\ Identifying and Estimating the Effects of \\ Unconventional Monetary Policy: \\ How to Do It And What Have We Learned?
}

\author{
Barbara Rossi* \\ ICREA-Univ. Pompeu Fabra, Barcelona GSE, and CREI
}

This Draft: July 31, 2020

Derivation of the following equation:

$\left(\begin{array}{c}\pi_{t} \\ y_{t} \\ r_{t}\end{array}\right)=\left(\begin{array}{ccc}\mathcal{B}_{11} & \mathcal{B}_{12} & 0 \\ \mathcal{B}_{21} & \mathcal{B}_{22} & 0 \\ \mathcal{B}_{31} & \mathcal{B}_{32} & \mathcal{B}_{33}\end{array}\right)\left\{c+B_{1} X_{t-1}+\ldots+B_{p} X_{t-p}+\left(\begin{array}{c}\varepsilon_{1, t} \\ \varepsilon_{2, t} \\ \varepsilon_{3, t}\end{array}\right)\right\}$

Note that:

$$
\begin{aligned}
& \left(\begin{array}{ccc}
B_{0,11} & B_{0,12} & 0 \\
B_{0,21} & B_{0,22} & 0 \\
B_{0,31} & B_{0,32} & B_{0,33}
\end{array}\right)^{-1} \\
& =\left(\begin{array}{ccc}
\frac{1}{B_{0,11} B_{0,22}-B_{0,12} B_{0,21}} B_{0,22} & -\frac{1}{B_{0,11} B_{0,22}-B_{0,12} B_{0,21}} B_{0,12} & 0 \\
-\frac{1}{B_{0,11} B_{0,22}-B_{0,12} B_{0,21}} B_{0,21} & \frac{1}{B_{0,11} B_{0,22}-B_{0,12} B_{0,21}} B_{0,11} & 0 \\
\frac{B_{0,11} B_{0,32}-B_{0,12} B_{0,31}}{B_{0,33}} & \frac{1}{B_{0,33}}
\end{array}\right) \\
& \equiv\left(\begin{array}{ccc}
\mathcal{B}_{11} & \mathcal{B}_{12} & 0 \\
\mathcal{B}_{21} & \mathcal{B}_{22} & 0 \\
\mathcal{B}_{31} & \mathcal{B}_{32} & \mathcal{B}_{33}
\end{array}\right) \\
& \left(\begin{array}{lll}
B_{0,31} & B_{0,32} & B_{0,33}
\end{array}\right)\left(\begin{array}{c}
\pi_{t} \\
y_{t} \\
r_{t}
\end{array}\right)=\pi_{t} B_{0,31}+r_{t} B_{0,33}+y_{t} B_{0,32} \\
& =c+B_{1} X_{t-1}+\ldots+B_{p} X_{t-p}+\varepsilon_{3, t} \\
& r_{t} B_{0,33}=-y_{t} B_{0,32}-\pi_{t} B_{0,31}+c+B_{1} X_{t-1}+\ldots+B_{p} X_{t-p}+\varepsilon_{3, t} \\
& r_{t}=-y_{t} B_{0,33}^{-1} B_{0,32}-\pi_{t} B_{0,33}^{-1} B_{0,31}+B_{0,33}^{-1} c+B_{0,33}^{-1} B_{1} X_{t-1}+\ldots+B_{0,33}^{-1} B_{p} X_{t-p}+B_{0,33}^{-1} \varepsilon_{3, t}
\end{aligned}
$$

